University of Zurich

Department of Economics

Working Paper Series

ISSN 1664-7041 (print)

ISSN 1664-705X (online)

Working Paper No. 251

\title{
Revealing "Mafia Inc."? Financial Crisis, Organized Crime, and the Birth of New Enterprises
}

Marco Le Moglie and Giuseppe Sorrenti

Revised version, December 2019 


\title{
Revealing "Mafia Inc."? Financial Crisis, Organized Crime, and the Birth of New Enterprises*
}

\author{
Marco Le Moglie ${ }^{\dagger}$ \\ Giuseppe Sorrenti ${ }^{\ddagger}$ \\ Bocconi University University of Zurich
}

December 2019

\begin{abstract}
We study the investment of organized crime in the legal economy. By using the shock induced on the Italian credit market by the 2007 subprime mortgage crisis, we document how provinces with a high organized crime presence have been impacted less by the crisis in terms of the establishment of new enterprises than provinces with a lower criminal infiltration. We provide evidence that the lower impact of the crisis is consistent with the presence of investments by organized crime in the legal economy. We corroborate this interpretation by comparing our results with the characterization made by the judicial authority of such investments and ruling out possible alternative explanations.
\end{abstract}

JEL classification: K42, L26.

Keywords: Mafia, organized crime, established enterprises, crisis.

${ }^{*}$ We thank Guglielmo Barone, Nadia Campaniello, Bruno Caprettini, Rocco D'Este, Gianmarco Daniele, Aureo De Paula, Marina Di Giacomo, Frederico Finan, Sergio Galletta, Nicola Gennaioli, David Hémous, Nicola Limodio, Maximilian Mähr, Federico Masera, Giovanni Mastrobuoni, Torsten Persson, Massimiliano Piacenza, Paola Profeta, Michele Rosenberg, David Stadelmann, Gilberto Turati, Fabian Waldinger, Fabrizio Zilibotti, and participants at several presentations for helpful comments on previous versions of this work. Special thanks to Paolo Pinotti and Francesco De Carolis for sharing data on public procurement. Financial support from the Swiss National Science Foundation (100018_165616) is gratefully acknowledged.

${ }^{\dagger}$ Dondena, Bocconi University (IT). E-mail: marco.lemoglie@unibocconi.it

${ }_{\ddagger}^{\ddagger}$ Department of Economics, University of Zurich (CH). E-mail: giuseppe.sorrenti@econ.uzh.ch 


\section{Introduction}

The presence of criminal organizations has been found to be largely detrimental for economic prosperity and development (Peri, 2004; Pinotti, 2015). Although organized crime usually operates through the use of violence, killings, and corruption to obtain power and territorial control, it also represents an important economic actor in many countries. According to the most recent estimates produced by the United Nations Office on Drugs and Crime (UNODC), the worldwide proceeds of organized crime in 2009 accounted for USD 2.1 trillion, with USD 1.6 trillion reinvested in the legal economy (UNODC, 2011).

In this work, we study organized crime's investment in the legal economy. ${ }^{1}$ This investment is important in different dimensions. On the one hand, it is one of the main channels used by criminal organizations to launder money (Ardizzi et al., 2014) and to make profits (UNICRI, 2016). On the other hand, it might be an important tool for organized crime to raise forms of social consensus in a segment of the population by acting as an alternative provider of capital and jobs (Gambetta and Reuter, 1995). ${ }^{2}$

We focus on Italy, a country that has been plagued by several criminal organizations since the nineteenth century, and we study the effect of the presence of organized crime on the establishment of new enterprises. We exploit the shock on the Italian credit market induced by the 2007 subprime mortgage crisis, and we compare in a Difference-in-Differences (DiD) setting the number of newly established enterprises in the pre- versus post-crisis period between provinces with and without mafia presence. We define mafia presence according to the Transcrime Mafia Index (TMI). ${ }^{3}$

Italy features three key elements underlying our identification strategy that allow us to detect the mafia investment in the legal economy. First, National Law 580/1993 requires each enterprise operating in Italy to be registered in the Registry of Enterprises. Therefore,

\footnotetext{
${ }^{1}$ For the remainder of the study, we will use the expressions organized crime, criminal organizations, and mafia as synonyms.

${ }^{2}$ Social consensus is one of the fundamental milestones of the empowerment of criminal organizations. For instance, the Sicilian Mafia in Italy rose to power in the nineteenth century as a movement fulfilling the need of the population to protect its land from predatory attacks (Bandiera, 2003). Similar cases have arisen worldwide, e.g. terrorist organizations and drug cartels.

${ }^{3}$ The TMI represents the most comprehensive definition of mafia presence. Here, as in the remainder of the paper, we use the expression with (without) mafia presence to mean with higher (lower) mafia presence.
} 
the registry contains both legal enterprises and those enterprises with hidden connections to organized crime. Second, the 2007 subprime mortgage crisis induced a credit contraction that was exogenous and hit areas with and without mafia presence with similar intensity. The crisis originated in the United States and rapidly propagated, without anticipation effects, to the Italian legal credit market inducing a sizable contraction in terms of credit granted to the entrepreneurial sector. We show that provinces with higher or lower levels of mafia presence experienced similar contractions in the years immediately after the onset of the crisis. Third, the crisis had a limited impact on mafia sources of capital and profits. UNODC (2011) reports no impact, or even some positive impact, of the crisis on mafia profits. As confirmed by the analysis of the main source of profits for Italian organized crime, i.e. the market of illegal drugs, organized crime mainly raises capital in markets barely affected by the economic downturn.

The above-described framework of mandatory enterprise registration, exogenous and homogeneous credit contraction across the country, and nondecreasing organized crime financial resources, makes mafia infiltration into the economy empirically detectable. Indeed, the onset of the subprime mortgage crisis depressed the supply of legal credit available for entrepreneurs similarly in provinces with and without a mafia presence. Consequently, the decrease in the number of established enterprises observed in the registry should be similar across provinces with and without mafia. However, in provinces with a mafia presence, the number of established enterprises should decrease less under the hypothesis that mafia invests in the legal economy. We test this hypothesis in our DiD setting.

The baseline analysis shows that provinces with higher mafia infiltration experience a less severe drop - about four percent - in the number of new enterprises established in the postcrisis period. This effect corresponds to a provincial average of 204 enterprises established every year in the post-crisis period due to mafia investment in the legal economy. ${ }^{4}$ Results are robust to a large number of tests for sample selection criteria, exclusion or inclusion of different sets of control variables, and possible residual endogeneity not captured by the DiD setting. More importantly, results do not depend on how mafia presence is defined.

\footnotetext{
${ }^{4}$ The number corresponds to 24 enterprises per 100,000 inhabitants. This number should be considered a lower bound for the number of mafia-connected enterprises operating in the legal economy. Indeed, our identification strategy highlights those enterprises that become visible due to the onset of the crisis.
} 
A detailed sensitivity analysis based on alternative available measures and definitions of mafia presence points to very stable and similar results for the mafia effect on established enterprises.

We run a set of validation, placebo, and falsification tests to corroborate the interpretation of the baseline results as evidence of mafia investment in the legal economy. We take advantage of the specific characteristics of the mafia investment in the legal economy revealed by the Italian judicial authority. Judicial evidence shows that mafia prefers to operate in the construction sector or under the legal form of a limited company. At the same time, mafia invests few resources in sectors characterized by high levels of innovation, such as the professional, scientific, and technical sector $(\mathrm{R} \& \mathrm{D})$. Our interpretation of the baseline results implies a sizable post-crisis effect of mafia presence in sectors or legal forms with a traditional presence of mafia. Conversely, there should be no or a reduced effect of mafia presence for sectors rarely preferred by mafia. The analysis confirms judicial evidence displaying a large post-crisis effect of mafia presence, specifically, less-severe drops in new enterprises in the construction sector and in enterprises with the legal form of a limited company; no effect arises for sectors avoided by mafia such as the R\&D.

Through additional falsification tests, we rule out the possibility that post-crisis changes in important determinants of the establishment of new enterprises could drive the results. These tests confirm that the baseline results are not driven by a different impact of the crisis on the demand for goods, a different degree of openness to the global market, or by differential post-crisis changes in the accessibility of economic resources such as public procurement or EU funds between provinces with and without mafia presence.

As a final step, we extend the analysis to closed enterprises and to the stock of operating (registered) enterprises, to provide an overview of the overall impact of mafia presence on the local entrepreneurial activity. ${ }^{5}$ The analysis points to a higher, but statistically insignificant, post-crisis increase in closures in provinces with mafia than in provinces without mafia. Practices such as usury and racketeering likely exacerbate entrepreneurs' difficulties in deal-

\footnotetext{
${ }^{5}$ The baseline analysis focuses on new enterprises to isolate mafia capital inflows to the legal economy as forms of investments and to mitigate the effect of other mafia interference in local entrepreneurial activity such as usury. Unioncamere (2014), SOS Impresa (2012), and Dalla Pellegrina (2008) show that new enterprises are less affected by illegal mafia lending practices and that these practices more commonly affect operating enterprises.
} 
ing with the consequences of the crisis. The effect of mafia presence on closed enterprises is smaller in size than the effect on new enterprises and this difference results in a positive and statistically insignificant net effect on registered enterprises.

This work represents the first attempt to reveal the actual investment of organized crime in the legal economy through evidence of its impact on the degree of local entrepreneurial activity. In particular, our study is the first to highlight the existence of positive-in-sign

effects of mafia territorial presence and provide an explanation for the persistence of such presence. In fact, although it is hard to empirically identify the specific scope underlying this investment, anecdotal and juridical evidence suggests that through the investment in the legal economy, organized crime is likely to accomplish tasks such as money laundering, generating profits, and raising forms of social consensus in the local population. The latter is often responsible for the ineffectiveness of policies targeted at reducing leniency toward organized crime. We also shed light on different aspects of mafia investment in the legal economy. Specifically, by confirming the existing qualitative evidence of mafia preferences when it comes to investing money in terms of economic sectors of activity and adopted legal forms, our research pinpoints where monitoring and vigilance should be improved.

The remainder of the paper is structured as follows. Section 2 briefly describes Italian organized crime. Section 3 introduces the data and the identification strategy underlying the analysis. Section 4 discusses the main results of the paper. Section 5 shows the validation, placebo, and falsification tests, while a robustness analysis for the main results of the work is conducted in Section 6. In Section 7, we extend the analysis to closed and registered enterprises. Section 8 concludes the work.

\section{Organized Crime in Italy}

Italy is characterized by the existence of a complex and well-established system of criminal activities managed by mafia-type organizations, which is exceptionally heterogeneous across the country. The Sicilian Mafia (Cosa Nostra) rose in the nineteenth century in response to the population's demand for private protection in a context of weak institutions and valuable natural resources (Gambetta, 1993; Bandiera, 2003; Buonanno et al., 2015; Dimico et al., 
2017). The expansion of Cosa Nostra in Sicily was contemporaneous with the birth of similar criminal organizations such as the Camorra in the Campania region and the 'Ndrangheta in the Calabria region.

After initial immobility, criminal organizations started to expand to the more productive and profitable central-northern regions. Factors such as the massive migration flows from Southern Italy triggered by the "Italian economic miracle" in the late 1950s until the early 1970s, and the confino law, which in the 1960s and 1970s imposed resettlement to different provinces on individuals likely to be involved in mafia-type criminal activities, pushed this expansion (Buonanno and Pazzona, 2014).

The effect of mafia presence is the topic of several empirical studies. Mafia expansion and presence is found to deteriorate political competition and to affect electoral outcomes (Daniele and Geys, 2015; Daniele and Dipoppa, 2017; De Feo and De Luca, 2017; Alesina et al., 2018; Acemoglu et al., 2019; Di Cataldo and Mastrorocco, 2019). Mafia presence also generates sizable losses in terms of economic resources such as local GDP or productivity (Peri, 2004; Albanese and Marinelli, 2013; Pinotti, 2015). Economic losses result from the mafia's ability to control local entrepreneurial activity and obtain monopolistic power by violent and intimidating behavior (Reuter et al., 1982; Reuter, 1987; Falcone, 1991; Reuter, 1993; Savona and Berlusconi, 2015). Moreover, in regions characterized by high levels of criminal activity, the cost of credit tends to increase (Bonaccorsi di Patti, 2009), foreign direct investments are lower (Daniele and Marani, 2011), and misallocation of public funds in the form of business subsidies occurs (Barone and Narciso, 2015; Daniele and Dipoppa, 2019).

This study complements the existing literature on organized crime by shedding light on possible positive-in-sign spillover effects of mafia presence due to its investment in the local legal economy. The understanding of possible positive-in-sign effects of mafia presence is important to understand how mafia obtains social consensus among part of the population. 


\section{$3 \quad$ Revealing the Mafia Investment}

In this section, we introduce the data used in the analysis and the elements underlying the identification strategy to unveil the mafia investment in the legal economy. We then describe the implementation of the identification strategy and discuss its main assumptions.

\subsection{Data}

We assemble a new panel data set containing information on established enterprises, mafia presence, and a set of control variables for determinants of the establishment of new enterprises. ${ }^{6}$ Each panel observation is at the province-year level. In the baseline analysis, we exclude from the sample provinces in the three regions where mafia originated, namely, Sicily, Campania, and Calabria, as these provinces considerably differ in structural and economic terms from the rest of the country. ${ }^{7}$ As a result of this sample selection, the data set covers 84 Italian provinces for $2003-2013 .^{8}$

The main dependent variable of interest is the number of new enterprises established at the province-year level. We exploit National Law 580/1993, which requires each Italian enterprise to register its activity on the Registry of Enterprises. This registration is mandatory for all enterprises that operate nationwide with the exception of professions such as lawyers or architects. We collect data on the number of new registrations in the Registry of Enterprises at the provincial level from the Italian National Institute of Statistics (ISTAT).

We adopt the Transcrime Mafia Index (TMI) as the baseline measure for mafia presence. ${ }^{9}$ The TMI constitutes the most comprehensive definition of mafia presence and includes features related both to territorial infiltration in terms of military occupation and the mafia's capacity to provide illegal goods and services. The TMI is a composite index at the provincial level and is constructed using records of those convicted of being in a mafia-type organization

\footnotetext{
${ }^{6}$ Appendix A.1 contains a detailed description of all data sources we used.

${ }^{7}$ In Section 6.1 we provide a robustness test for our baseline analysis based on the sample containing all Italian regions.

${ }^{8}$ We start the analysis in 2003 because of pre-2003 data unavailability for the control variables described below.

${ }^{9}$ The TMI was developed by Calderoni (2011). In the baseline analysis, we rely on the version of the index provided in the report Mafia Investments, funded by the Italian Ministry of Internal Affairs and the European Union (Ministry of the Interior, 2013). Appendix A.2 provides a detailed description of the TMI.
} 
as defined in Law 646 and art.416-bis, murders committed by mafia members, city councils dissolved because of mafia infiltration, and assets seized due to organized crime.

We define mafia presence as an indicator variable Mafia based on the tertiles of the TMI distribution. We opt for the use of tertiles of the TMI distribution to obtain a clearer contrast between the group of provinces with and without mafia presence. However, as there is no univocal way to define mafia presence, Section 4 reports a detailed sensitivity analysis based on different measures and definitions for mafia presence. The analysis reassures that none of the baseline results depend on the measure or definition we use for mafia presence.

The indicator Mafia takes the value of one for provinces within the last tertile of the TMI distribution, and zero for provinces within the first or second tertile of the distribution. ${ }^{10}$ Figure A.3 validates the choice of combining the first and second tertiles of the TMI as the "control group" of the baseline analysis. Indeed, the first and second tertiles of the TMI distribution shape the establishment of new enterprises in a similar way. Figure 1 shows the territorial distribution of the TMI according to the tertiles of its distribution.

Our data also include a set of control variables for determinants of the establishment of new enterprises potentially correlated with local mafia presence. Control variables capture the structure of the local credit market as well as the characteristics of the economic, institutional, and social environments.

Big banks, which are able to deal with higher and riskier credit costs, represent a good approximation for credit market conditions. The characteristics of the local credit market might shape entrepreneurial activity as well as the perpetration of criminal activities such as usury or money laundering (Dalla Pellegrina, 2008). We gather data on the fraction of big banks (banks whose total value of traded funds is greater than EUR 26 billion) over the total number of banks to proxy the characteristics of the local credit market.

For the economic environment, we calculate the share of self-employment over total employment in a certain province to control for the local degree of entrepreneurship. Selfemployment positively correlates with business creation (Faggio and Silva, 2014). As some economic sectors, such as tourism and waste-treatment sectors, are particularly at risk of

\footnotetext{
${ }^{10}$ We compute the tertiles of the TMI distribution after excluding the three regions not part of the main analysis, namely Sicily, Campania, and Calabria. In the remainder of the paper, we label provinces "with" mafia versus provinces "without" mafia according to this definition.
} 
criminal infiltration, we focus on these two sectors as markers of provincial attractiveness for mafia (Ministry of the Interior, 2013; Savona, 2015). We measure the relevance of the tourism and the waste treatment sectors with an index of attractiveness of tourism-related consumption and the per-capita quantity of produced waste.

We proxy the quality of the institutional and social environment with control variables for the efficiency of the judicial system, urban population, blood donations, and newspaper circulation. The efficiency of the judicial system is measured as the provincial average duration in days of a bankruptcy trial. The efficiency of the judicial system stands out as one important factor that positively affects the level of entrepreneurial activity (Chemin, 2009) and negatively affects crime (Blanco, 2012). We compute the fraction of population living in urban areas at the provincial level as both new-enterprises formation (Delfmann et al., 2014) and crime (Christens and Speer, 2005) are affected by the urban-living population. We also collect data on newspaper circulation within each province and the regional average number of blood donations to account for the level of human and social capital respectively (Acs and Armington, 2004; Buonanno et al., 2009; Nieto and González-Álvarez, 2016). ${ }^{11}$ Table A.1 provides summary statistics for our sample.

\subsection{The Identification Strategy}

Our identification strategy relies on three elements: (i) the registration in the Registry of Enterprises required of each enterprise operating in Italy; (ii) the exogeneity and geographical homogeneity of the credit contraction induced by the 2007 subprime mortgage crisis; and (iii) a lower impact of the crisis on mafia sources of capital and profits than the impact observed in the legal credit market.

The first element of the identification strategy is the mandatory registration of Italian enterprises. This registration allows to use information about licit markets to infer insights about illicit activities (Zitzewitz, 2012). Illicit trafficking and activities often interface (and interfere) with legal markets. This relation leaves detectable traces as it is subjected to the laws and rules governing legal activities. As a result of the mandatory registration in the Registry of Enterprises, the registry contains information on the universe of enterprises

\footnotetext{
${ }^{11}$ Data about blood donations are unavailable at the provincial level.
} 
operating in the country, among which is a subgroup with hidden connections to criminal organizations.

The second element of the identification strategy is the shock induced by the 2007 subprime mortgage crisis. Ideally, in order to compare possible consequences induced by the shock in provinces with different levels of mafia presence, we would need a sizable and exogenous credit shock. Moreover, the shock would need to similarly hit provinces with and without mafia presence. The subprime mortgage crisis fulfills these two requirements.

The shock induced by the subprime mortgage crisis was not anticipated by the Italian credit market as it started in the United States in 2007 and rapidly spread to the rest of the world. This lack of anticipation is confirmed by the difference between interbank interest rates, namely the LIBOR for the United States and EURIBOR for the European Union, and the interest rate on the equivalent index swap rate. This difference is a common measure of liquidity of the banking system and the counterparty risk. The measure reports negligible differences up to the second half of 2007. In August 2007, the difference suddenly starts to rapidly increase to its peak in the second half of 2008 with the breakup of Lehman Brothers. The loss of confidence among financial institutions was directly reflected in their supply of credit to borrowers. According to the diffusion index created by the European Central Bank (ECB) and the Bank Lending Survey (BLS), which is a measure capturing the evolution of credit standards, Italian loan officers started to report a tightening of the lending standards almost contemporaneous to the beginning of the financial turmoil in the United States in 2007. ${ }^{12}$

The tightening of lending standards affected the amount of credit available for Italian entrepreneurs. Figure 2 plots the rate of change of credit supplied to the entrepreneurial system based on data by the Bank of Italy. Each point in the figure represents the variation in the credit supplied to the entrepreneurial system with respect to the same quarter of the previous year. No anticipation effect appears in the pre-crisis period. Credit grows at a constant rate in the initial 2004-2005 period. In 2006, the provision of credit shows increasing (positive) growth rates. The (relative) increasing trend in credit granted to the entrepreneurial system suddenly stops in 2007 and becomes almost flat before starting a

\footnotetext{
${ }^{12}$ Appendix A.3 provides the description analysis of the spread and the diffusion index.
} 
decreasing trend.

Figure 2 also shows that the credit contraction similarly impacts provinces with and without mafia presence. The analysis in Table 1 confirms the similarity through a more formal regression model. We aggregate the rate of change of credit supplied to the entrepreneurial system at the province-year level. In column (1), we regress the rate of change of credit on the interaction term between Mafia and Crisis, which is an indicator variable for 20072013. In column (2), we replicate the analysis by focusing on the interaction terms between Mafia and indicator variables for each year in the 2004-2013 period. The interaction between Mafia and the indicator variable for the year 2006 (last year pre-crisis) represents the reference category for all point estimates. The results in column (1) and (2) highlight that none of the point estimates is statistically significant. In the pre-crisis period, provinces with and without mafia appear on similar trends in terms of credit provided to the entrepreneurial system. Also in the post-crisis period, provinces with and without mafia remain on similar trends, which confirms the homogeneity of the impact of the subprime mortgage crisis.

The third element of the identification strategy requires the subprime mortgage crisis to affect mafia profits and capital with a lower intensity with respect to the hit on the legal credit market. The report UNODC (2011) indicates that in the post-crisis years 2007-2009, the revenues generated by organized crime in Italy through illicit traffic remained not only largely stable, but even showed a small increase. This increase suggests that Italian organized crime might have benefited from the crisis. We empirically test this assumption with an analysis of the Italian illegal drugs market. Organised Crime Portfolio (2015) and Savona and Berlusconi (2015) show that drug dealing generates the highest profits for organized crime in Italy. According to Transcrime, drug dealing generates EUR 7.7 billion per year, an amount almost double that of criminal organizations' second source of revenue, i.e. racketeering.

Figure 3 investigates the possible impact of the crisis on the Italian market for illegal drugs in the period of interest for this study. We focus on data by the European Monitoring Centre for Drugs and Drug Addiction on four different drugs - amphetamines, cocaine, heroin, and cannabis - and on four different market indicators - the total number of offenses for drug use (Figure 3-a), the total number of seizures (Figure 3-b), the total quantity of drugs seized (Figure 3-c), and the average price (Figure 3-d). Illegal drug demand (and consumption) 
is stable over time. Figure 3-a shows that the number of offenses related to drug use has been almost constant since 2007. The exception is cannabis offenses, which saw a (slight) decrease. On the supply side of the market, both the volume, i.e. Figures 3-b and 3-c, and prices, i.e. Figure 3-d, remain almost stable during the entire period, except for an increase in the quantity of cannabis seized and a modest drop in the price of cocaine and heroin. ${ }^{13}$

To summarize, the context of mandatory enterprise registration, exogenous and homogeneous credit contraction across provinces with and without mafia, and illegal capital invested in the legal economy makes mafia-connected enterprises more detectable given that provinces with stronger mafia presence should experience a less-severe post-crisis drop in the number of new enterprises registered every year.

\subsection{The Difference-in-Differences Estimator}

We implement the identification strategy described in Section 3.2 in a DiD setting based on two alternative specifications: a pooled DiD setting and an event study setup.

In the first specification, we pool post-crisis years and compare the number of new enterprises (i) before and after the outbreak of the subprime mortgage crisis, and (ii) between provinces with and without mafia. The DiD baseline equation of interest in this case is:

$$
\text { NewEnterprises }_{i, t}=\beta_{0}+\beta_{1} \text { Mafia }_{i} \times \text { Crisis }_{t}+\mathbf{X}_{i, t}^{\prime} \boldsymbol{\beta}+\alpha_{i}+\gamma_{t}+\delta_{m, t}+\varepsilon_{i, t} \quad,
$$

where $i$ defines the province, $m$ the macro region, i.e. north versus the rest of the country, and $t$ the year. NewEnterprises is the logarithm of the number of new enterprises per 100,000 inhabitants. Mafia $\times$ Crisis is an indicator variable for the interaction between our variable for mafia presence, Mafia, and an indicator variable Crisis for the period starting in 2007. The model also includes the vector $\mathbf{X}_{i t}$ with the control variables introduced in Section 3.1, province fixed effects $\left(\alpha_{i}\right)$ for time-invariant heterogeneity at the provincial level, year fixed effects $\left(\gamma_{t}\right)$ for common shocks across provinces, and macro region-year fixed effects $\left(\delta_{m, t}\right)$ to capture structural differences in the reaction to the crisis across macro regions $m . \varepsilon_{i, t}$ is the

\footnotetext{
${ }^{13}$ The after-2006 adjustments in both the demand and supply sides of the cannabis market are likely driven by the 2006 change in Italian legislation due to Law 49/2006. This law eliminated the distinction between "soft" and "hard" drugs, thus equating cannabis consumption with the consumption of harder drugs.
} 
error term of the model.

We aim to consistently estimate the coefficient $\beta_{1}$ for Mafia $\times$ Crisis. This parameter captures different trends in the number of new enterprises between provinces with and without mafia after the hit of the subprime mortgage crisis. In general, the crisis negatively hits the number of new enterprises established across the Italian territory (see Figure 4). Therefore, positive values of the parameter $\beta_{1}$ would imply a less severe drop in the outcome variable for provinces with mafia presence compared to provinces without mafia presence. On the contrary, a negative parameter would imply a more severe drop in the outcome variable for provinces with mafia than for those without mafia.

In the second specification, we consider an event study setup. The event study allows us to understand the timing of the possible mafia effect and its evolution over time. It takes the following form:

$$
\begin{array}{r}
\text { NewEnterprises } \text { E }_{, t}=\beta_{0}+\sum_{\tau \in(-4,6), \tau \neq-1} \boldsymbol{\beta}_{\tau} \text { Mafia }_{i} \times \mathbb{1}(t+\tau)+ \\
+\mathbf{X}_{i, t}^{\prime} \boldsymbol{\beta}+\alpha_{i}+\gamma_{t}+\delta_{m, t}+\varepsilon_{i, t}
\end{array}
$$

The event study setup takes the same form as Equation 1, but instead of pooling different years in a pre-crisis versus a post-crisis period, we interact Mafia with an indicator variable for each year $(t+\tau)$. We label as $t$ the year of the subprime mortgage crisis outbreak (i.e. 2007). The pre-crisis period covers the years from $t-4$ to $t-1$, while the post-crisis period covers the years from $t$ to $t+6$. We consider the last pre-crisis year $t-1$ as the reference year.

The DiD estimation strategy requires the parallel trends assumption to hold, i.e., the trends in the number of new enterprises for provinces with and without mafia need to be parallel in the pre-crisis period. Figure 4 provides a graphical and a more formal test for the parallel trends assumption. The graphical test shows the evolution over time of the number of enterprises between provinces with and without mafia. The second test is based on the event study setup. Specifically, the number of new enterprises established at the provinceyear level is regressed on the set of interaction terms between Mafia and indicator variables 
for each year. ${ }^{14}$ Figures 4 -a and 4-b report the analysis for the period of interest for this study, i.e. 2003-2013. As one possible concern of this analysis is that the pre-crisis period might be unable to capture possible secular trends, in Figures 4-c and 4-d we replicate the same analysis focusing on a wider pre-crisis period starting in 1997, the first year with data for the Registry of Enterprises.

The graphical analysis in Figures 4-a and 4-c suggests that the parallel trends assumption holds in our framework. We plot both the trends in the number of new enterprises for provinces with and without mafia presence and the linear fit for such trends in the pre- and post-crisis periods. In the pre-crisis period, the trend for the number of new enterprises for provinces with no mafia presence fairly mimics the trend for those provinces with organized crime. The dotted line for the linear interpolation in the pre- and post-crisis periods suggests that the trends for provinces with and without mafia are parallel and increasing before the crisis, while they start decreasing and diverging in the post-crisis period. The divergence points to a less severe reduction in the number of post-crisis established enterprises for provinces with mafia than without mafia.

The event study setup in Figure 4-b confirms the existence of parallel trends. Provinces with and without mafia are on similar trends in the pre-crisis period. With respect to the last pre-crisis year $t-1$, none of the three estimated pre-crisis coefficients is statistically significant at the conventional levels, neither separately nor jointly $(p$-value $=0.34)$, and point estimates are close to zero. Figure 4-d confirms the existence of parallel trends and that when considering a wider time period, any clear secular trend in the number of established enterprises is observed when provinces with and without mafia are compared (joint test $p$-value $=0.21)$. Also, the event study setup seems to point to a positive effect of mafia presence, namely, a less severe post-crisis drop in the number of established enterprises, for provinces with mafia compared to provinces without mafia. ${ }^{15}$

Given that the parallel trends assumption holds, the DiD identification strategy does not require the group of provinces with and without mafia presence to be balanced in terms of observable characteristics. However, in our framework, the comparison of the control

\footnotetext{
${ }^{14}$ The event study specification only includes province fixed effects, year fixed effects, and macro regionyear fixed effects. Section 4 describes the analysis with control variables.

${ }^{15}$ We will discuss the post-crisis period more in detail in Section 4.
} 
variables between provinces with and without mafia might help clarify whether the two groups of provinces are fairly similar with respect to a set of observable characteristics. Table 2 compares the average pre-crisis values of our control variables for provinces with versus without mafia presence. Provinces with and without mafia presence are fairly similar with respect to control variables, with two variables turning out to be statistically different. Prior to the onset of the crisis, the percentage of big banks is larger in provinces with mafia (0.404 versus 0.329$)$ and the percentage of self-employment is slightly larger in provinces without mafia (0.285 versus 0.269$)$. These two imbalances do not constitute a threat to our identification strategy. First, we include in our specifications control variables for big banks and self-employment. Second, in Figure A.4, we report the analysis with the event study setup of control variables that shows that big banks and self-employment in Figures A.4-a and A.4-b are on parallel trends in the pre-crisis period. All the pre-crisis coefficients are indeed very small in size and statistically insignificant. Trends also remain parallel in the post-crisis period. Parallel trends in control variables reassure us that there is no differential trends with the potential to affect our baseline estimates.

\section{Baseline Results}

Table 3 reports the OLS estimates of Equation 1. We estimate five different specifications with the $(\log )$ number of new enterprises as the dependent variable. The specification in column (1) only includes province fixed effects. Column (2) includes province and year fixed effects. Column (3) includes province and year fixed effects and macro region-year fixed effects for the north versus the rest of the country. Column (4) includes province and year fixed effects and the set of control variables described in Section 3.1. Column (5) includes province and year fixed effects, macro region-year fixed effects, and the set of control variables. We use Conley spatial HAC standard errors (Conley, 1999, 2008) to consider both spatial and serial correlations of mafia presence. We set the spatial lag to $200 \mathrm{~km}$ and the temporal lag to 11 years, i.e. the entire length of our observational window. ${ }^{16}$

\footnotetext{
${ }^{16}$ The correlogram analysis in Figure A.5 suggests the choice of $200 \mathrm{~km}$ for the spatial lag. The correlogram shows that the spatial correlation of mafia presence tends to vanish at $200 \mathrm{~km}$ from the centroid of the main city in each province.
} 
The estimates in Table 3 show that provinces with mafia presence experience a less severe post-crisis reduction in the number of newly established enterprises with respect to provinces without mafia. The effect of mafia presence is similar across specifications with improvements in estimates precision with the progressive inclusion in the model of control variables. For this reason, in the remainder of the paper, we refer to the most complete specification in column (5) as the "complete model."

Considering the complete model, provinces with mafia presence experience a 3.9 percent less-severe post-crisis reduction in the number of established enterprises with respect to provinces without mafia. In absolute terms, this effect implies a provincial average of 204 enterprises - 24 per 100,000 inhabitants - established every year in the post-crisis period due to mafia investment in the legal economy.

In Figure 5, we perform the analysis in the event study setup based on the complete model. First, as for the analysis without control variables in Figure 4, provinces with and without mafia are on parallel trends in the pre-crisis period (joint significance $p$-value $=0.44$ ). Point estimates for the pre-crisis effect of mafia presence are very close to zero and never statistically distinguishable from zero. Second, in the post-crisis period a less severe droppositive coefficients - in the number of established enterprises is observed in provinces with mafia. Point estimates for the effect of mafia presence start to increase over time, producing larger estimates with the worsening of the effect of the crisis. The peak of the effect is reached at year $t+5$ with an estimated effect above five percent.

As the definition of mafia is not univocal, in Table 4 we replicate the analysis by relaxing each element of the definition of Mafia used in the baseline. First, we abstract from the use of the last tertile of the TMI distribution by using different quantiles of the distribution. Second, we relax the use of an indicator variable and we rely on a continuous index for mafia presence. Third, we replicate the analysis by using all available measures other than the TMI, for mafia presence. All the results are obtained with the complete model.

In column (1) of Table 4, we define mafia presence as an indicator variable based on quartiles instead of tertiles. Therefore, the indicator for mafia presence takes the value of one for provinces within the fourth quartile of the TMI distribution, and zero otherwise. Results are similar with this alternative definition for mafia presence. The point estimate 
for the post-crisis effect of mafia presence remains positive and strongly significant. The size of the effect becomes larger in magnitude than in the baseline. The increase in magnitude suggests that the choice of the fourth quartile might better isolate provinces with high levels of mafia presence and infiltration in the legal economy.

In column (2), mafia is redefined as the fifth quintile of the TMI distribution. The postcrisis effect of mafia presence is positive, statistically significant, and slightly larger in size than the in the analysis based on the fourth quartile. The analysis in columns (1) and (2) suggests that the choice of different quantiles of the TMI distribution to define mafia presence has negligible effects on our main findings.

In column (3) we abstract from the definition of Mafia as an indicator variable and rely on the continuous measure of TMI. Therefore, we redefine our variable of interest Mafia $\times$ Crisis as the interaction term of the continuous TMI with the indicator variable Crisis. The post-crisis effect of mafia presence is positive and statistically significant. Larger values of the mafia index imply less-severe post-crisis drops in the number of established enterprises. This analysis suggests that the use of a continuous versus an indicator variable for mafia presence conveys similar conclusions for the effect of mafia presence on the local entrepreneurial activity.

The TMI measure used to define mafia presence is based on criminal records for 20002011. The inclusion of some post-crisis years might raise concerns about the possible endogeneity of the index with respect to the onset of the subprime mortgage crisis. Indeed, mafia might have geographically expanded its action during the crisis and this expansion might correlate with the way the crisis hit newly infiltrated provinces. Our analysis is unlikely to be affected by this concern for three reasons. First, the expansion of organized crime to new provinces is not an instantaneous process and it requires time to mafia to establish connections and actively infiltrate the local economy. Our analysis is based on a limited post-crisis timeframe making this process more unlikely. Second, in our baseline analysis, mafia presence is defined based on the last tertile of the TMI distribution. This choice allows us to mainly capture provinces with relevant traces of mafia presence. To establish relevant traces or to become part of this more-infiltrated group of provinces would require some time. Third, in columns (4)-(9), we show that the mafia effect in the baseline analysis is robust 
to the use of different mafia indexes based exclusively - or almost exclusively - on pre-crisis records.

In columns (4)-(7), we replicate the analysis by relying on an older, but less refined, version of the TMI (TMI-pre) based almost exclusively on pre-crisis data, i.e. 1983-2009. ${ }^{17}$ In column (4) we define mafia with an indicator for provinces within the third tertile of the TMI-pre distribution. In column (5) we rely on the fourth quartile of TMI-pre, while in column (6) we use the fifth quintile to define mafia presence. In column (7) we exploit the continuous index TMI-pre. All the results obtained with the TMI-pre remain similar to those obtained with the TMI. This analysis suggests that the time period covered by records used to construct the TMI does not drive the main findings.

In columns (8) and (9), we abstract from using the TMI and replicate the analysis by relying on different measures for mafia presence. ${ }^{18}$ In column (8), we rely on the Power Syndicate Index (PSI) provided by Fondazione RES. The PSI maps mafia degree of control of a territory in terms of military occupation, e.g. mafia-type association, murders by mafia members, and racketeering practices. The index is based on average records for these types of crimes over 2004-2007. We redefine Mafia as an indicator for those provinces with some, but marginal, evidence of mafia presence (PSI $>0)$. This alternative definition compares provinces with (at least) a marginal trace of mafia territorial presence with those without any sign of criminal infiltration. The analysis shows that the coefficient for the post-crisis effect of mafia presence remains positive and statistically significant.

In column (9), we proxy mafia presence through the measure used in Pinotti (2015) based on the number of cases brought pursuant to Article 416-bis of the Italian Criminal Code. Article 416-bis captures the adherence of Italian mafias to the theoretical framework of Schelling (1971). Pinotti (2015) states that "Article 416-bis aimed explicitly at mafia organisations, defined as those groups that exploit the power of intimidation granted by the membership in the organisation, and the condition of subjugation and omertà that descends from it, to commit crimes and acquire the control of economic activities, concessions, au-

\footnotetext{
${ }^{17}$ The TMI used in the baseline analysis has several improvements over the older version used here, including new and more detailed sources of data. The new version also accounts for the special dimensions of mafia presence across neighboring provinces.

${ }^{18}$ Appendix A.4 provides further details on the alternative measures for mafia presence used in this analysis. Figure A.6 shows mafia location according to these alternative measures.
} 
thorisations, and public contracts (page F207)." We redefine Mafia as an indicator for those provinces with at least one case brought pursuant art.416-bis in the 2003-2006 period (CasesArt.416-bis $>0$ ). As for the PSI, this definition for mafia presence compares provinces with traces of mafia territorial presence with those without any sign of criminal infiltration. Column (9) displays a positive a statistically significant point estimate for the post-crisis effect of mafia presence. The analysis in columns (8) and (9) reassure that the choice of different measures or indexes for mafia presence implies similar results for the effect of mafia presence on established enterprises.

\section{Validation, Placebo, and Falsification Tests}

We run validation, placebo, and falsification tests for our baseline results. Validation and placebo tests serve to support the interpretation of the baseline results as evidence of mafia investment in the legal economy. Falsification tests allow us to rule out potential explanations, other than mafia investment, that would drive our baseline results. This section shows the analysis based on the event study setup for the complete model. Table A.2 reports the results with the standard DiD approach. The results obtained with the two specifications are similar.

Mafia has strong sectoral and legal form preferences when it comes to investing its money. We would expect to find larger post-crisis mafia effects in sectors or legal forms preferred by mafia, while there should be no or a reduced effect of mafia presence for sectors rarely preferred by mafia. We test this hypothesis by using the number of established enterprises in specific sectors or with a specific legal form as the dependent variable.

The Ministry of the Interior (2013) and Savona (2015) illustrate mafia preferences for its investment in the legal economy. Italian mafia-type organizations are particularly active in the construction sector; around 30 percent of mafia-type organizations firms seized by Italian authorities operate within this sector. The construction sector is characterized by high movement of capital and high levels of profitability, allowing criminal organizations to launder money. In terms of legal forms, limited companies are by far the first option for criminal organizations (46.6 percent). Limited companies are particularly easy to establish 
and require a minimum initial capital of EUR 10,000. Moreover, they guarantee limited liability of business partners. On the contrary, mafia does not heavily invest in the professional, scientific, and technical sector (R\&D), as it is highly professionalized and involves a very high level of competition and know-how.

Figures 6-a and 6-b report the analysis of the construction sector and limited companies, respectively. For both, the analysis shows that provinces with and without mafia are on parallel trends pre-crisis. After the outbreak of the crisis, provinces with mafia report a statistically significant less-severe drop with respect to provinces without mafia-positive point estimates for the post-crisis effect of mafia presence - in the number of established enterprises in the construction sector and in the number of established limited companies. Point estimates are in both cases larger than the one in the baseline estimates confirming mafia preference for the construction sector and for limited companies. Moreover, as in the baseline, the effect becomes larger with the exacerbation of the consequences of the crisis.

Figure 6-c depicts the case of the R\&D sector. Provinces with and without mafia report parallel trends pre-crisis. Post-crisis, provinces with and without mafia remain on parallel trends. None of the coefficients for differential post-crisis effects by mafia presence is statistically significant at the conventional levels. This evidence reinforces the interpretation of the effect of mafia presence in the baseline as driven by mafia investment in the legal economy. Indeed, while we find large mafia effects in sectors or legal forms usually preferred by mafia, we do not find any mafia effect on sectors not infiltrated by mafia such as R\&D.

Five additional falsification tests corroborate the interpretation of our baseline results. The aim of these falsification tests is to confirm that the mafia effect in the baseline analysis is not driven by post-crisis changes in determinants of the establishment of new enterprises that potentially changed in different ways between provinces with and without mafia.

We start by covering demand factors such as GDP per capita and unemployment rate. Differential post-crisis performance in terms of provincial GDP or unemployment might explain the treatment effect of the baseline analysis. In other words, we need to verify that provinces with mafia have not experienced less-severe consequences on the demand for goods induced by the crisis. Otherwise, less-severe consequences of the crisis on the demand for goods in provinces with mafia might explain the less-severe post-crisis decline in 
the number of established enterprises. Figures 6-d and 6-e show the analysis of provincial GDP per capita and provincial unemployment rate as dependent variables, respectively. The analysis of GDP suggests that in the post-crisis period, provinces with and without mafia are on parallel trends. The same occurs for the unemployment rate. The crisis similarly hit provinces with and without mafia in terms of GDP and unemployment. Therefore, such demand factors are unlikely to drive our baseline results.

We then analyze the degree of openness to international markets as measured by the level of exports over GDP. Provinces less connected to the global market might be less affected by the global crisis. If the effect of the crisis was less severe in provinces with mafia presence due to lower connections to the global market, then our estimates might reflect a differential impact of the crisis between provinces rather than differences in the level of mafia investment in the legal economy. We analyze the pre-crisis degree of openness to international markets as well as its evolution in the post-crisis period. First, in our sample, provinces with and without mafia presence display similar values of exports. The average pre-crisis values amount to 20 and 22 percent of GDP for provinces with and without mafia, respectively. The difference between the two values is statistically insignificant. This evidence reassures that our baseline results are unlikely driven by the level of connection to international markets.

Second, we also test for possible differences in the post-crisis period in the relative importance of exports between provinces with and without mafia presence. If in the post-crisis period exports become relatively less important in provinces with mafia presence than in provinces without mafia presence, this change would contribute to the positive effect of mafia presence in the baseline analysis. Figure 6-f shows the analysis with the share of provincial exports with respect to GDP as the dependent variable. With the exception of a weakly significant positive mafia effect in year $t+2$, all the post-crisis point estimates are close to zero and statistically insignificant. It is unlikely that factors related to the degree of openness to international markets drive our baseline results.

We run two additional falsification tests to verify whether differential post-crisis changes in financial and economic constraints faced by provinces with and without mafia might explain our baseline results. We focus on the amount of public procurement and EU funds granted to Italian provinces. If the amount of funds granted to provinces with mafia drops 
less post-crisis than in provinces without mafia, this might drive the mafia effect in the baseline analysis.

We start by analyzing public procurement as a considerable share of mafia's profits comes from bidding for public procurement contracts. The analysis aims to test whether in the post-crisis period we observe differential changes in the amount of public procurement between provinces with and without mafia. To perform the analysis, we calculate the total amount of public procurement at the provincial level for 2003-2013 per 100,000 inhabitants (logarithmic scale). ${ }^{19}$ Figure 6-g shows the analysis with the amount of public procurement at the province-year level as the dependent variable. In the post-crisis period, provinces with and without mafia display parallel trends in terms of public procurement. Therefore, the analysis of public procurement reassures that the mafia effect in the baseline analysis is unlikely driven by post-crisis changes in public procurement.

As a last falsification test, we analyze EU funds granted to Italian provinces. Provinces with more mafia are usually granted a higher share of EU funds, which are deemed to be less susceptible to the economic cycle. To perform the analysis, we calculate the total EU funds granted at the provincial level per 100,000 inhabitants (logarithmic scale). Unfortunately, data for Italian provinces are only available since $2007 .{ }^{20}$ Due to this data limitation, we restrict the event study analysis to the post-crisis period and use $t$ as the reference value for EU funds granted to provinces with and without mafia. Figure 6-h reports the post-crisis analysis with EU funds as the dependent variable. Provinces with and without mafia are on parallel trends, specifically, no differential changes by mafia presence, regarding the amount of EU funds received in the post-crisis period. Despite the restricted sample of years used in this analysis, the evidence in the figure suggests that differential changes by mafia presence in EU funds granted post-crisis are unlikely to explain the mafia effect in the baseline analysis. The analysis of EU funds confirms that the evolution of post-crisis financial and economic constraints faced by Italian provinces is unlikely to drive our baseline analysis.

\footnotetext{
${ }^{19}$ The data on public procurement are elaborated by De Carolis et al. (2019) from records of the National Anticorruption Authority (ANAC). The data contain the universe of public procurement contracts for projects above EUR 40,000.These contracts represent 70 percent of all public procurement contracts. Data on contracts with a value below EUR 40,000 are limited and only available since 2011.

${ }^{20}$ The data are collected by OpenCoesione. OpenCoesione provides data on all projects financed by European Structural Funds with a national cofinancing requirement. The data availability does not allow for the pooled DiD analysis of EU funds in Table A.2.
} 


\section{Robustness Analysis}

In this section, we provide a set of robustness tests for our baseline results. In particular, we test whether our baseline estimates change in response to the use of different sample selection criteria, to the consideration of possible secular trends in control variables, to the inclusion of additional control variables for financial resources availability at the local level, and to the use of an IV approach to deal with potential residual endogeneity of mafia presence.

\subsection{Sample Selection}

In the baseline analysis, we restrict the estimation sample by excluding those regions where mafia originated. In Table 5, we test this sample selection criterion by running two extra specifications. First, we replicate the analysis by focusing on the whole sample of Italian regions. Second, in addition to the three regions where mafia originated (Sicily, Campania, and Calabria) excluded in the baseline, we also exclude the Apulia region. We include Apulia in the baseline estimation because the active criminal group in this region, the United Sacred Crown, began only in relatively recent times as the result of the diffusion of the Camorra (Pinotti, 2015).

Column (1) of Table 5 reports the estimate of the complete model with all Italian regions. To run this analysis, we reconstruct the indicator Mafia based on the third tertile of the TMI distribution of all Italian regions. The point estimate for the post-crisis mafia effect is positive, statistically significant, and larger in size than the baseline estimate. The choice to exclude regions where mafia originated seems conservative as the inclusion of these regions, which are characterized by a massive mafia presence, amplifies the magnitude of the mafia effect on established enterprises.

In column (2) of Table 5, we estimate the complete model excluding the Apulia region in addition to the exclusion of Sicily, Campania, and Calabria. We reconstruct the indicator Mafia based on the third tertile of the TMI distribution after excluding the Apulia region. The point estimate for the post-crisis mafia effect remains positive and statistically significant, although it is slightly lower in magnitude. 


\subsection{Trends for Control Variables}

We test whether our results are affected by heterogeneity in the reaction to the crisis due to different levels of the control variables (Galiani et al., 2005; Biderman et al., 2010). To run the test, we define as the predetermined value for each control variable the observation for the year $t-1$, the last year prior to the onset of the crisis. Then we include in the model the interaction terms between the predetermined value and indicator variables for each year.

Table 6 reports the analysis. In column (1), we include the interaction terms between the percentage of big banks and indicator variables for each year to capture the trends in the credit market structure. In column (2), we include interaction terms for the economic environment, i.e. the provincial level of self-employment, the per capita quantity of produced waste, and the index of attractiveness of tourism-related consumption. In column (3), we include the interaction terms for the controls for the institutional and social environment, i.e. the average duration in days of a bankruptcy trial, urban population, newspaper circulation, and blood donations. Finally, in column (4), we show the results for the model with trends for all the control variables.

All the specifications with trends for control variables display a positive and significant effect of post-crisis mafia presence on established enterprises. The size of the effect is similar across the different specifications in columns (1) to (4) and similar to the one in the baseline analysis. With emphasis on the more demanding model in column (4) with trends for all control variables, we find a 2.4 percent less-severe post-crisis drop in established enterprises in provinces with mafia versus provinces without mafia presence.

\subsection{Controlling for Financial Resources}

In this section, we test whether changes in the availability of credit and financial resources at the local level potentially explain the results of the baseline analysis. We start with the analysis of the Italian Domestic Stability Pact (DSP) and then we consider the provision of credit granted by the banking system to entrepreneurs.

The DSP is an Italian law that requires municipalities with populations above certain thresholds to fulfill specific requirements in terms of public deficits and public debt. The main 
requirement is to balance public yearly revenues and expenditures. The DSP was introduced in Italy at the end of the 1990s for municipalities with more than 5,000 inhabitants, but it remained almost unenforced given the absence of a proper set of penalties. The DSP was reformed in 2008 with the introduction of severe penalties to municipalities not fulfilling the DSP requirements. Coviello et al. (2017) and Venturini (2018) show that the 2008 reform of the DSP induced austerity policies and the tightening of budgets, therefore impacting financial and economic resources available to municipal governments.

With the tightening of the DSP, the coefficient for Mafia $\times$ Crisis might capture a variation in the extent of investment of the public sector in the economy. This is unlikely to be the case for two main reasons. First, a descriptive analysis of the percentage of municipalities under DSP at the provincial level suggests that provinces with mafia have a higher percentage of municipalities under DSP than provinces without mafia. Therefore, if anything, the possible effect of the DSP in our framework would lower, and not inflate, the point estimate for the post-crisis effect of mafia presence. Second, in column (1) of Table 7, we re-estimate the complete model by adding the interaction terms between the fraction of municipalities under DSP in each province and indicator variables for each year. This specification takes into account the heterogeneity in the percentage of municipalities under DSP in each province and captures yearly differences across provinces in the reaction to the crisis due to such heterogeneity. The point estimate for the post-crisis mafia effect remains similar to the one of the baseline analysis.

As a further robustness test, we show the estimates of the complete model with the inclusion of a control variable for the amount of credit granted to the entrepreneurial system at the province-year level. This inclusion serves to test whether our results depend on differential post-crisis trends in credits granted to the entrepreneurial system between provinces with and without mafia. The results in column (2) of Table 7 show that the inclusion of the control for credits does not remarkably affect the point estimate for the post-crisis mafia effect. 


\subsection{Residual Endogeneity of Mafia Presence}

The geographical presence of mafia across the Italian territory is nonrandom. We implement an IV approach to deal with this potential residual endogeneity concern. While our DiD strategy with fixed effects for provinces, years, and macro region-year fixed effects already rules out many potential concerns related to such endogeneity, the IV analysis helps in addressing the residual (potential) bias induced by time-varying unobserved heterogeneity at the provincial level.

We build upon Buonanno and Pazzona (2014) in our IV analysis. Precisely, we use an Italian law - the confino law -implemented in the 1960s and in the 1970s as an instrument for current mafia presence. The confino law was introduced to fight mafia's power in the regions of origin of mafia by resettling mafia members to other Italian regions. The law ended up expanding mafia activity to previously noninfiltrated regions.

The IV analysis exploits the number of people resettled across Italian provinces up to 1974, which is the last year with publicly available data, under the confino law as an instrument for mafia presence. ${ }^{21}$ In our framework, the external instrument needs to fulfill three requirements. First, the instrument needs to be exogenous with respect to the characteristics driving the current establishment of enterprises at the provincial level. Second, the instrument needs to be relevant in affecting current mafia locations. Third, the instrument needs to affect the current birth of new enterprises only through its effect on the current mafia distribution across provinces (exclusion restriction).

We start with the discussion of exogeneity. The relocation of mafia members was fairly exogenous. Mafia members resettled by the confino law were not allowed to choose their own destination and they ended up in provinces without specific characteristics related with entrepreneurial activity, e.g. more populated, more urban, or more developed provinces. The law did not state precise criteria for the selection of the resettlement location. Decisions about resettlement locations were made by the judge who headed the tribunal where the mafia member was residing with very vague instructions about the characteristics of the hosting cities or town. This vagueness resulted in mafia members usually being assigned to

\footnotetext{
${ }^{21}$ Appendix A.1 describes the variable for resettled mafia members. Figure A.7 plots the geographical distribution of the instrument across the Italian territory.
} 
small towns on the outskirts of cities to make it easier for authorities to control their actions. Buonanno and Pazzona (2014) show that the resettlement was plausibly exogenous with respect to local socio-economic conditions. Any significant difference arises when regressing different measures for the confino law, e.g. number of relocated mafia members, on different pre-law measures for local socio-economic conditions such as population density, GDP per capita, or crime rate (Table 3 , page 79 ).

For the relevance of the instrument, Buonanno and Pazzona (2014) show that the confino law represented one of the actual determinants of the expansion of mafia-type organizations outside the regions where they originated. Our first-stage estimates confirm the importance of the confino law in shaping the expansion of mafia across the Italian territory.

Finally, in terms of the exclusion restriction, it is fair to assume that the number of mafia members resettled by the confino law in the 1960s and 1970s only impacts the current rate of new enterprises through its impact on the likelihood of currently observing mafia in a specific province.

The first stage of the IV analysis takes the following form:

$$
\text { Mafia }_{i} \times \text { Crisis }_{t}=\delta_{0}+\delta_{1} \text { Resettled }_{i} \times \text { Crisis }_{t}+\mathbf{X}_{i, t}^{\prime} \boldsymbol{\beta}+\alpha_{i}+\gamma_{t}+\delta_{m, t}+\varepsilon_{i, t}
$$

where $i$ defines the province, $m$ the macro region and $t$ the year. Resettled is the total number of people resettled (received) within each province by $1974 .^{22}$ Resettled $\times$ Crisis represents the interaction of the instrument with the indicator variable for the post-crisis. $\mathbf{X}_{i, t}$ is a vector containing the same control variables as in Equation 1, while $\alpha_{i}, \gamma_{t}$ and $\delta_{m, t}$ capture fixed effects at the province, year, and macro region-year levels, respectively.

Table 8 shows the results of the IV estimation. As in the baseline, we estimate five different specifications with the (log) number of new enterprises as the dependent variable. In column (1) we only include province fixed effects. In column (2) we include province and year fixed effects. In column (3) we include province and year fixed effects and macro region-year fixed effects. In column (4) we include province and year fixed effects and the usual set of control variables. In column (5) we include province and year fixed effects, macro

\footnotetext{
${ }^{22}$ We use the classification of Italian provinces in force when resettlement took place. This classification includes 77 provinces out of the 84 used in the baseline analysis.
} 
region-year fixed effects, and the set of control variables. In both the first and the second stages, we allow for spatial $(200 \mathrm{~km})$ and serial (11 years) correlation of standard errors.

The first-stage estimates are similar for the five different specifications with the instrument that displays a positive and strongly significant coefficient. Provinces that received more mafia members due to the confino law have higher levels of mafia presence decades after the resettlement. The point estimate implies that ten individuals resettled increase the probability of being in the last tertile of the TMI by about seven percentage points. ${ }^{23}$

The second-stage estimates highlight two important conclusions. On the one hand, the IV analysis confirms that provinces with mafia experience a less-severe post-crisis drop in established enterprises than provinces without mafia. The point estimate for the post-crisis effect of mafia presence is indeed always positive, less precisely estimated, and becomes statistically significant in the specifications including control variables (columns 4 and 5). On the other hand, although the instrument displays high statistical significance in the first stage, the analysis of the Kleibergen-Paap Wald F-statistic seems to reveal a slight weakness of the instrument that suggests a cautious interpretation of the second-stage estimates size. Despite this limitation, the IV results align with baseline estimates, therefore suggesting that the endogeneity concern due to mafia nonrandom location is unlikely to drive the main findings of this study.

\section{The Case of Closed and Registered Enterprises}

In this section, we extend our baseline analysis to shed light on the overall mafia effect on local entrepreneurial activity. Mafia presence and investment in the legal economy affect the establishment of new enterprises in addition to the closure of existing enterprises. This study aims to disentangle mafia capital inflows to the legal economy through actual investments from other types of interference in local entrepreneurial activity such as usury. For this reason, we mainly focus on new enterprises. New enterprises are less affected by illegal mafia lending practices. Indeed, although it is impossible to completely rule out the possibility that

\footnotetext{
${ }^{23} \mathrm{An}$ average of 27 resettled mafia members were received by each province. Provinces with mafia received an average of 35 resettled mafia members, and provinces without mafia received an average number of 24 resettled mafia members.
} 
new entrepreneurs could eventually turn to organized crime to borrow capital for starting a new business, Unioncamere (2014), SOS Impresa (2012), and Dalla Pellegrina (2008) suggest that closed or already existing enterprises are more affected by these practices.

We start with the analysis of closed enterprises. The post-crisis effect of mafia presence on closed enterprises is dual. On the one hand, in the post-crisis, mafia presence might induce a negative mafia effect on closures, e.g. fewer closed enterprises or last-resort effect, due to mafia investment in the legal economy. Due to worse economic conditions, entrepreneurs might resort to organized crime to obtain resources to run their business more than in the pre-crisis period. On the other hand, mafia presence and practices, i.e. usury and racketeering, deteriorate the local arena and the local economy (Reuter et al., 1982; Reuter, 1987, 1993) with consequences that can be exacerbated during recessions. For example, with less disposable income due to the crisis, entrepreneurs are more likely than in the pre-crisis period to struggle to repay loans taken at usurious rates. This results in a positive post-crisis effect of mafia presence on closures (more closed enterprises, disruptive effect). The point estimate for the post-crisis effect of mafia presence clarifies whether the last-resort effect or the disruptive effect prevail in the post-crisis period.

We also analyze registered enterprises, namely the stock of enterprises operating in a province at a specific point in time. The mafia effect on registered enterprises reveals the combination, or net effect, of the mafia effect on established and closed enterprises. The number of registered enterprises is:

$$
\text { Registered }_{i, t}=\text { Registered }_{i, t-1}+\left(\text { NewEnterprises }_{i, t}-\text { Closed }_{i, t}\right) \quad,
$$

where $i$ is the province and $t$ the year. NewEnterprises is the number of new enterprises and Closed is the number of closed enterprises.

Table 9 reports the analysis of closed and registered enterprises based on our complete model. For both closed and registered enterprises, the outcome is expressed as the logarithm of the number of enterprises per 100,000 inhabitants. Column (1) of the table shows the case of closed enterprises. The point estimate for Mafia $\times$ Crisis is positive and statistically insignificant, with an effect that amounts to about 2.6 percent. Although statistically 
insignificant and smaller than the effect on established enterprises, the positive sign of the effect on closures might be interpreted as weak evidence of a post-crisis disruptive effect of mafia presence slightly outperforming the last-resort effect.

Column (2) shows the analysis of registered enterprises. The evidence of a positive effect of mafia presence on new enterprises larger than the statistically insignificant increase in closures shapes a positive mafia effect on registered enterprises. The statistically insignificant effect amounts to 1.4 percent, an effect size similar to the difference between the point estimate for the post-crisis mafia effect for established with respect to closed enterprises. In a period in which the stock of operating enterprises tends to decline, registered enterprises operating in provinces with a mafia presence experience a less-severe drop, albeit statistically insignificant, than in provinces without mafia.

\section{Conclusion}

In this work, we investigate organized crime's investment in the Italian legal economy by exploiting the mandatory registration required by both legal and illegal enterprises. We implement a DiD empirical strategy based on the comparison of new enterprises established before and after the onset of the 2007 subprime mortgage crisis, and between provinces with high levels of mafia presence and provinces with low levels of mafia presence.

We find that provinces more infiltrated by organized crime experience a less severe postcrisis drop in established enterprises than less-infiltrated provinces. Quantitatively, in the post-crisis period the establishment of new enterprises drops by four percent less in more infiltrated provinces than in less-infiltrated provinces. This estimate is likely to represent a lower bound for the actual extent of mafia investment in the legal economy, since it only captures the part of such investment that became detectable due to the crisis. The results of this study are robust to the use of different definitions and measures for mafia presence, to different sample selection criteria, and to the use of different empirical specifications.

Validation and placebo tests based on judicial evidence corroborate the interpretation of the mafia effect on new enterprises as evidence of mafia investment in the legal economy. On the other hand, a set of falsification tests rules out the possibility that other determinants 
of the establishment of new enterprises different from mafia investment, e.g. openness to the global market or allocation of funds, drive our results.

The analysis in this paper highlights the desirability of adopting standard repression policies against criminal organizations complemented by institutional interventions, e.g. provision of credit or programs to enhance employment opportunities to undermine the roots of the social consensus obtained through mafia investment in the legal economy. Moreover, by showing mafia preferences in terms of sectors and legal forms, we underline where vigilant monitoring and stricter legislation should be improved. Finally, our research suggests that during recessions, vigilance and monitoring should be improved even further to preempt greater future organized crime infiltration in the economy. As pointed out by Mario Draghi during his speech to the Italian parliamentary anti-mafia commission in 2009: "During recession firms see their cash flows dry up and watch the market value of their assets fall. Both these phenomena render companies more easily assailable by organized crime."

\section{References}

Acemoglu, D., De Feo, G., De Luca, G. D., 2019. Weak States: Causes and Consequences of the Sicilian Mafia. The Review of Economic Studies (forthcoming).

Acs, Z., Armington, C., 2004. The Impact of Geographic Differences in Human Capital on Service Firm Formation Rates. Journal of Urban Economics 56(2), 244-278.

Albanese, G., Marinelli, G., 2013. Organized Crime and Productivity: Evidence from FirmLevel Data. Rivista Italiana degli Economisti 28(4), 367-394.

Alesina, A., Piccolo, S., Pinotti, P., 2018. Organized Crime, Violence, and Politics. The Review of Economic Studies 86(2), 457-499.

Ardizzi, G., Petraglia, C., Piacenza, M., Schneider, F., Turati, G., 2014. Money Laundering as a Crime in the Financial Sector: A New Approach to Quantitative Assessment, with an Application to Italy. Journal of Money, Credit and Banking 46(8), 1555-1590. 
Bandiera, O., 2003. Land Reform, the Market for Protection, and the Origins of the Sicilian Mafia: Theory and Evidence. Journal of Law, Economics, and Organization 19(1), 218244.

Barone, G., Narciso, G., 2015. Organized Crime and Business Subsidies: Where Does the Money Go? Journal of Urban Economics 86, 98-110.

Biderman, C., De Mello, J. M. P., Schneider, A., 2010. Dry Laws and Homicides: Evidence from the São Paulo Metropolitan Area. The Economic Journal 120(543), 157-182.

Blanco, L., 2012. The Impact of Reform on the Criminal Justice System in Mexico. RAND Working Paper WR-948.

Bonaccorsi di Patti, E., 2009. Weak Institutions and Credit Availability: The Impact of Crime on Bank Loans. Questioni di Economia e Finanza (Occasional Papers)—Bank of Italy 52 .

Buonanno, P., Durante, R., Prarolo, G., Vanin, P., 2015. Poor Institutions, Rich Mines: Resource Course and the Origins of the Sicilian Mafia. The Economic Journal, 125(586), $175-202$.

Buonanno, P., Montolio, D., Vanin, P., 2009. Does Social Capital Reduce Crime? The Journal of Law and Economics 52(1), 145-170.

Buonanno, P., Pazzona, M., 2014. Migrating Mafias. Regional Science and Urban Economics $44,75-81$.

Calderoni, F., 2011. Where is the Mafia in Italy? Measuring the Presence of the Mafia across Italian Provinces. Global Crime 12(1), 41-69.

Chemin, M., 2009. The Impact of the Judiciary on Entrepreneurship: Evaluation of Pakistan's "Access to Justice Programme". Journal of Public Economics 93(1), 114-125.

Christens, B., Speer, P., 2005. Predicting Violent Crime Using Urban and Suburban Densities. Behavior and Social Issues 14, 113-127. 
Conley, T., 1999. GMM Estimation with Cross Sectional Dependence. Journal of Econometrics $92(1), 1-45$.

Conley, T. G., 2008. Spatial Econometrics. In: Durlauf, S. N., Blume, L. E. (Eds.), The New Palgrave Dictionary of Economics, Palgrave Macmillan, London.

Coviello, D., Marino, I., Nannicini, T., Persico, N., 2017. Direct Propagation of a Fiscal Shock: Evidence from Italy's Stability Pact. Mimeo.

Dalla Pellegrina, L., 2008. Illegal Finance, Interest Rates and Bank Lending: The Missing Supply Side of Usury. Global Business and Economics Review 10(3), 265-283.

Daniele, G., Dipoppa, G., 2017. Mafia, Elections and Violence Against Politicians. Journal of Public Economics 154, 10-33.

Daniele, G., Dipoppa, G., 2019. Doing Business Below the Line: Screening, Mafias and Public Funds. BAFFI CAREFIN Centre Research Papers No. 2018-98.

Daniele, G., Geys, B., 2015. Organised Crime, Institutions and Political Quality: Empirical Evidence from Italian Municipalities. The Economic Journal 125(586), F233-F255.

Daniele, V., Marani, U., 2011. Organized Crime, the Quality of Local Institutions and FDI in Italy: A Panel Data Analysis. European Journal of Political Economy 27(1), 132-142.

De Carolis, F., Fisman, R., Pinotti, P., Vannutelli, S., 2019. Corruption in Procurement: New Facts from Italian Government Contracting. Mimeo.

De Feo, G., De Luca, G. D., 2017. Mafia in the Ballot Box. American Economic Journal: Economic Policy 9(3), 134-167.

Delfmann, H., Koster, S., McCann, P., Van Dijk, J., 2014. Population Change and New Firm Formation in Urban and Rural Regions. Regional Studies 48(6), 1034-1050.

Di Cataldo, M., Mastrorocco, N., 2019. Organised Crime, Captured Politicians and the Allocation of Public Resources. TEP Working Paper No. 1018. 
Dimico, A., Isopi, A., Olsson, O., 2017. Origins of the Sicilian Mafia: The Market for Lemons. The Journal of Economic History 77(4), 1083-1115.

Faggio, G., Silva, O., 2014. Self-Employment and Entrepreneurship in Urban and Rural Labour Markets. Journal of Urban Economics 84, 67-85.

Falcone, G., 1991. Cose di Cosa Nostra. Fabbri Editori.

Galiani, S., Gertler, P., Schargrodsky, E., 2005. Water for Life: The Impact of the Privatization of Water Services on Child Mortality. Journal of Political Economy 113(1), 83-120.

Gambetta, D., 1993. The Sicilian Mafia. The Business of Private Protection. Harvard University Press, Boston.

Gambetta, D., Reuter, P., 1995. Conspiracy Among the Many: The Mafia in Legitimate Industries, pp. 99-120. Palgrave Macmillan, London.

Ministry of the Interior, 2013. Progetto PON Sicurezza 2007-2013. Gli Investimenti delle Mafie.

Nieto, M., González-Álvarez, N., 2016. Social Capital Effects on the Discovery and Exploitation of Entrepreneurial Opportunities. International Entrepreneurship and Management Journal 12(2), 507-530.

Organised Crime Portfolio, 2015. From Illegal Markets to Legitimate Businesses: The Portfolio of Organized Crime in Europe. Final Report of Project OCP, Transcrime.

Peri, G., 2004. Socio-Cultural Variables and Economic Success: Evidence from Italian Provinces 1951-1991. Topics in Macroeconomics 4(1).

Pinotti, P., 2015. The Economic Costs of Organized Crime: Evidence from Southern Italy. The Economic Journal 125(586), 203-232.

Reuter, P., 1987. Racketeering in Legitimate Industries: A Study in The Economics of Intimidation. Technical report, RAND Corporation.

Reuter, P., 1993. The Cartage Industry in New York. Crime and Justice 18, 149-201. 
Reuter, P., Rubinstein, J., Wynn, S., 1982. Racketeering in Legitimate Industries: Two Case Studies. Washington DC: National Institute of Justice.

Savona, E., 2015. The Businesses of Italian Mafias. European Journal on Criminal Policy and Research 21(2), 217-236.

Savona, E. U., Berlusconi, G., 2015. Organized Crime Infiltration of Legitimate Businesses in Europe: A Pilot Project in Five European Countries. Final Report of Project ARIEL, Transcrime.

Schelling, T. C., 1971. What is the Business of Organized Crime? Journal of Public Law 20, 71-84.

SOS Impresa, 2012. Le Mani della Criminalità sulle Imprese.

UNICRI, 2016. Organized Crime and the Legal Economy — The Italian Case.

Unioncamere, 2014. Studio Conoscitivo sul Fenomeno dell'Usura.

UNODC, 2011. Estimating Illicit Financial Flows Resulting From Drug Trafficking and Other Transnational Organized Crimes.

Venturini, F., 2018. The Unintended Composition Effect of the Subnational Government Fiscal Rules: The Case of Italian Municipalities. SIEP Working Paper 70.

Zitzewitz, E., 2012. Forensic Economics. Journal of Economic Literature 50(3), 731-769. 


\section{Figures and Tables}

Figure 1: Geographical Distribution of the TMI

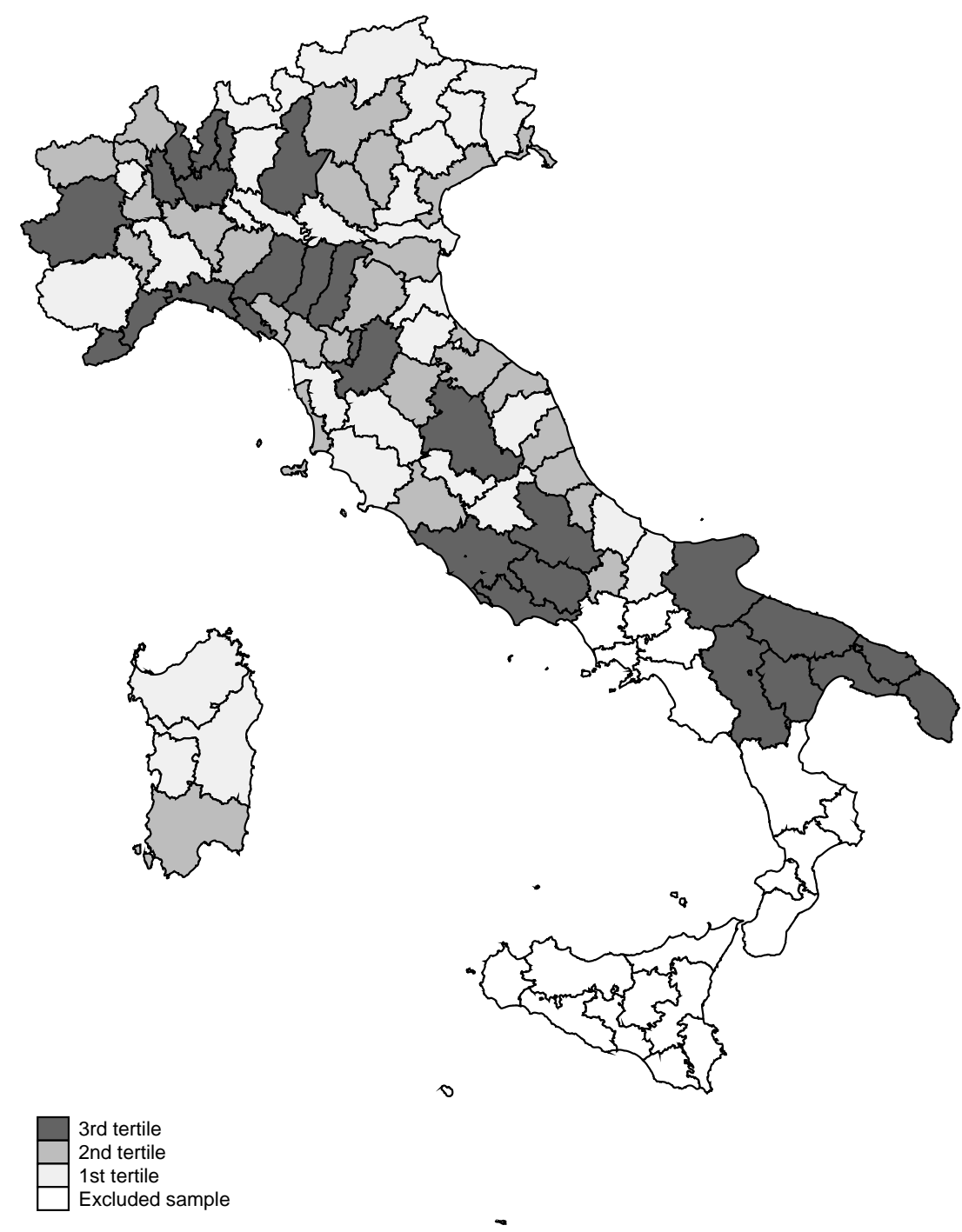

Note: This figure shows the geographical distribution of the Transcrime Mafia Index (TMI). The map shows the tertiles of the TMI distribution across the Italian provinces. The more intense the filling color of a province, the higher the tertile to which it belongs. White-colored provinces are those excluded from the sample. 
Figure 2: Change in the Supply of Legal Credit to the Entrepreneurial System

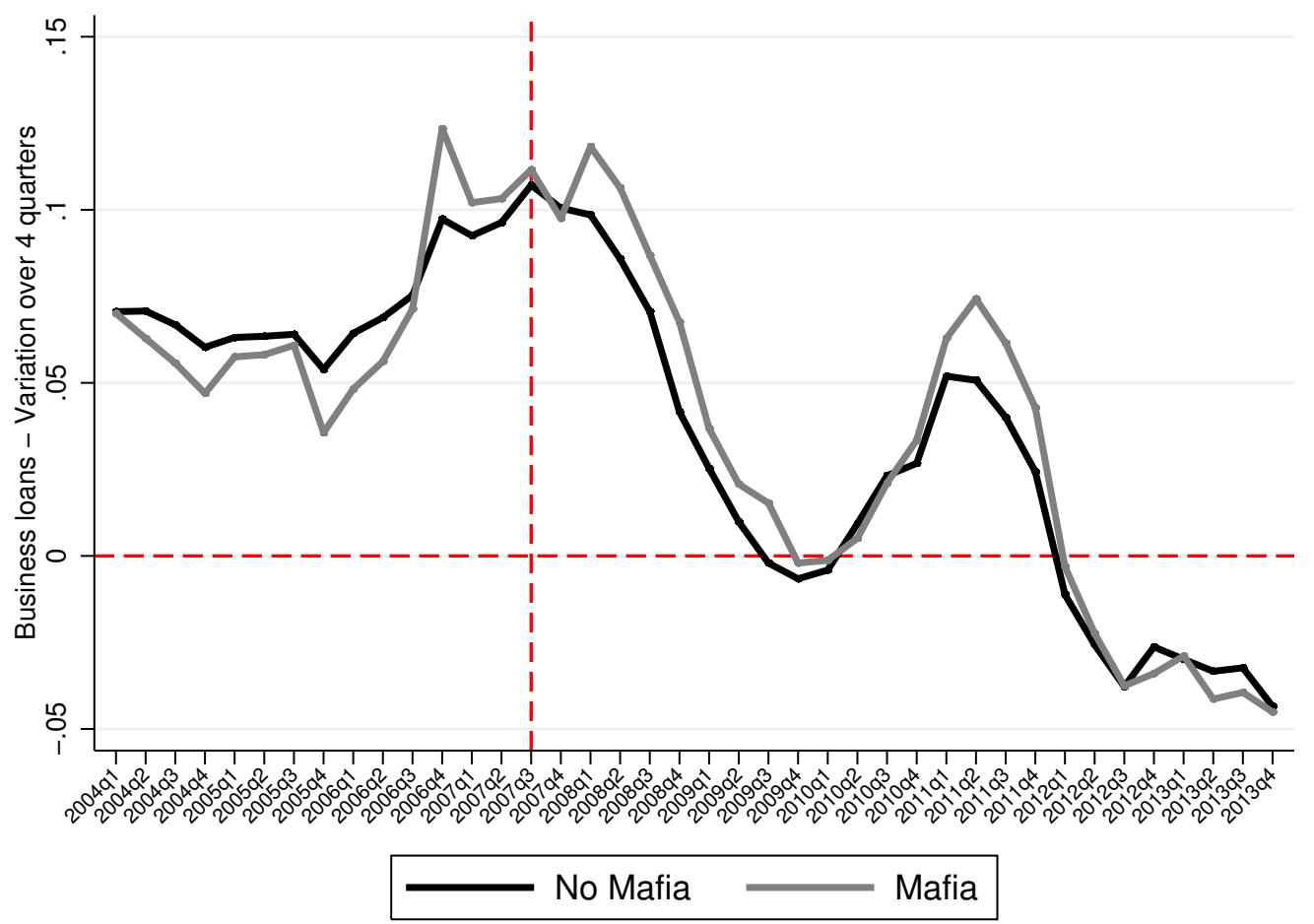

Note: This figure shows the change over four quarters in the amount of credit granted to the Italian entrepreneurial system. The comparison is between provinces within the first two tertiles of the TMI distribution (No Mafia, black line) and those belonging to the third tertile (Mafia, gray line). The vertical red line indicates the quarter of the year in which the financial turmoil at the root of the subprime mortgage crisis started. 
Figure 3: The Market for Illegal Drugs in Italy
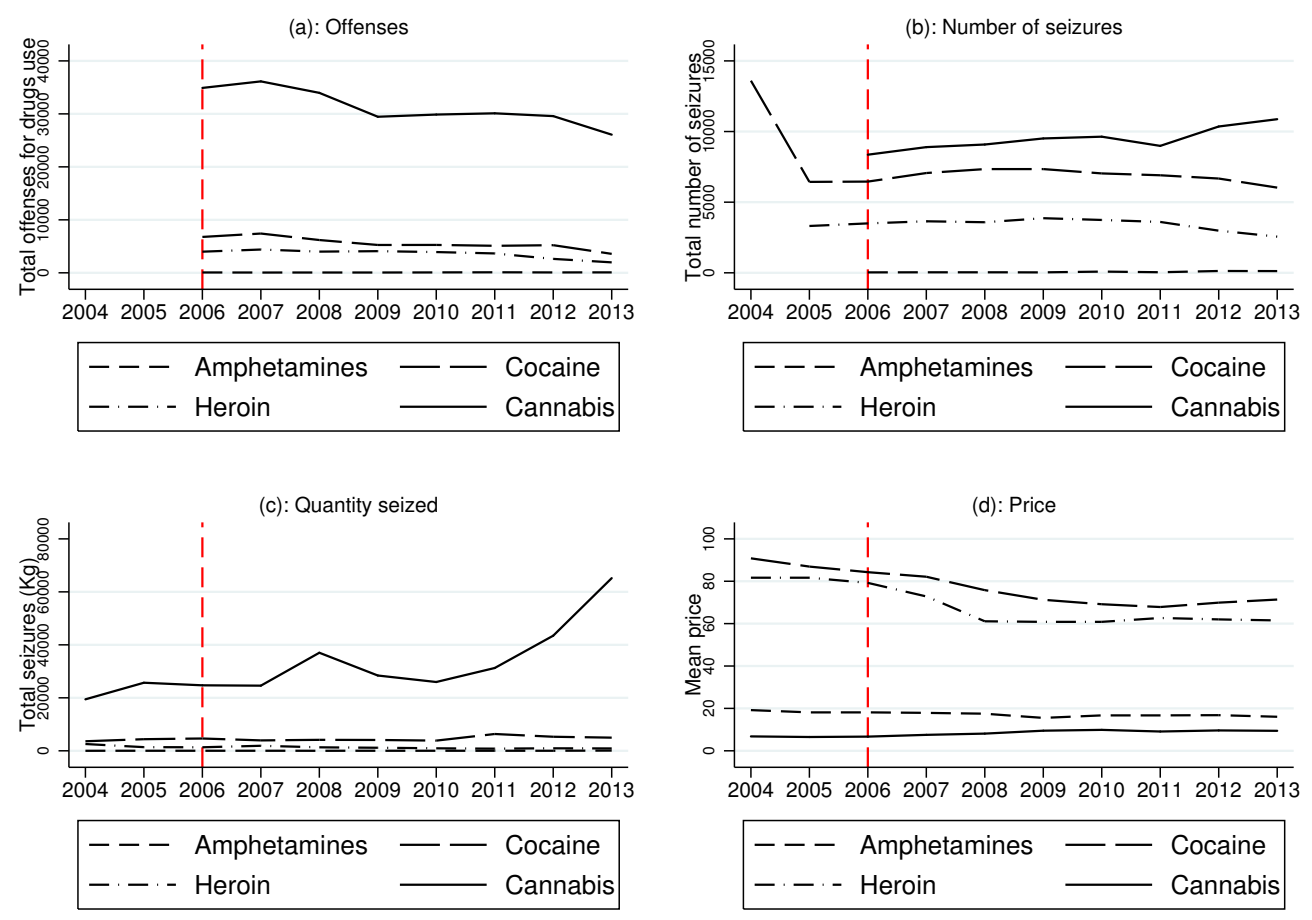

Note: This figure shows the evolution over time of the Italian market for illegal drugs. Figure (a) reports the time trend of the total number of offenses for drug use. Figure (b) reports the time trend of the total number of seizures. Figure (c) reports the total number of kilograms seized. Figure (d) reports the estimated average price. Each figure displays the case of amphetamines, cocaine, heroin, and cannabis. The analysis is based on data provided by the European Monitoring Centre for Drugs and Drug Addiction. 
Figure 4: Testing Parallel Trends
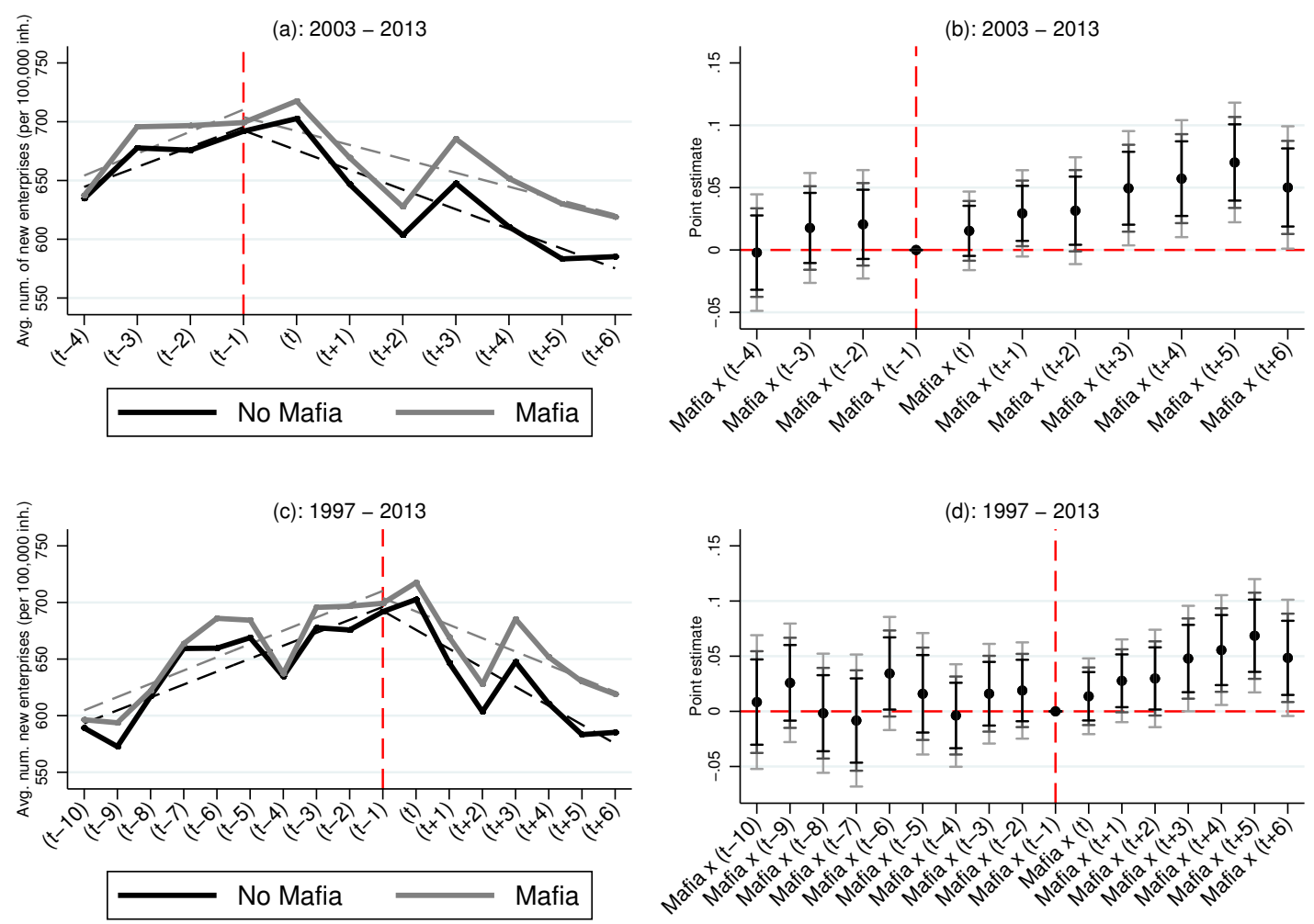

Note: This figure shows the evolution over time of the effect of mafia presence on established enterprises. Figures (a) and (b) show the analysis for 2003-2013. Figures (c) and (d) show the analysis for 1997-2013. Figures (a) and (c) report the trends in the number of established enterprises and the linear fit for such trends by mafia presence. The comparison is between provinces within the first two tertiles of the TMI distribution (No Mafia, black line) and those belonging to the third tertile of the distribution (Mafia, gray line). Figures (b) and (d) report the event study analysis. The dependent variable is the number of new enterprises (per 100,000 inhabitants, logarithmic scale). The variables Mafia $\times(t+\tau)$ are interaction terms of Mafia - an indicator variable taking the value of one for provinces within the third tertile of the TMI distribution - with indicator variables for each year. Period $t$ identifies the starting year of the subprime mortgage crisis and the red vertical dashed line visually separates the pre-crisis and the post-crisis periods. The model only includes province fixed effects, year fixed effects, and macro region-year fixed effects. Figures (b) and (d) report each point estimate of Mafia $\times(t+\tau)$ for the effect of mafia presence in a specific year together with the $90 \%$ (black), 95\% (gray) and 99\% (light gray) confidence intervals. Confidence intervals are based on spatially $(200 \mathrm{~km})$ and serially (11 years) correlated standard errors. 
Figure 5: Mafia Presence and New Enterprises - Event Study

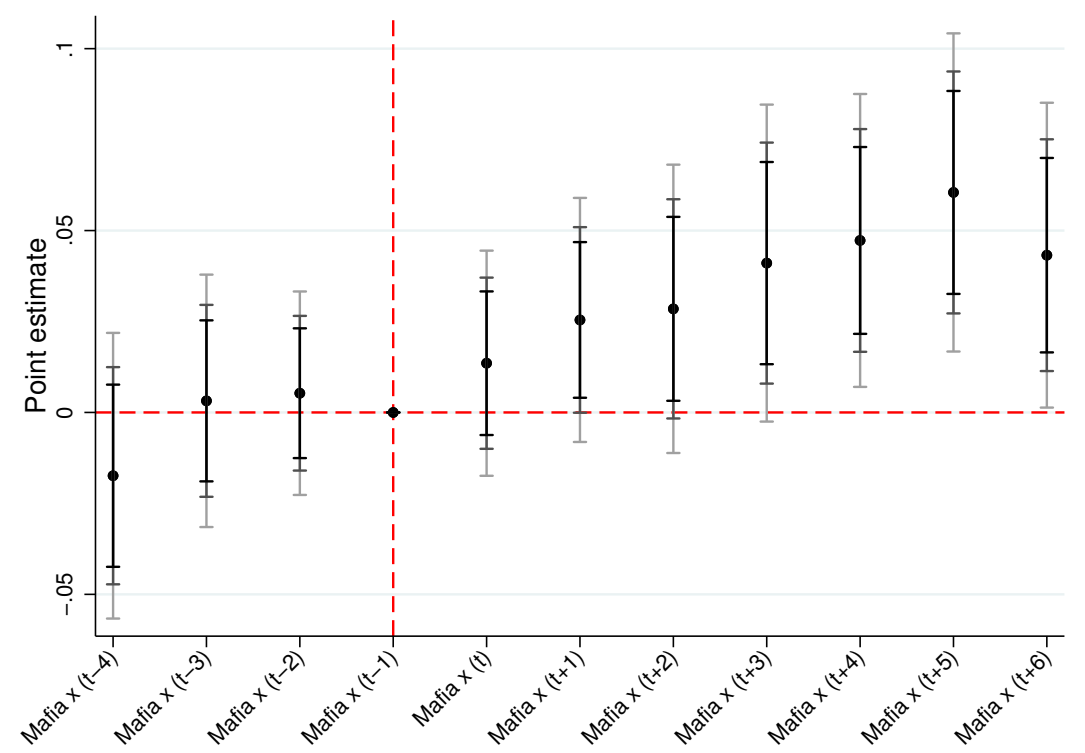

Note: This figure shows the evolution over time of the effect of mafia presence on established enterprises. The dependent variable is the number of new enterprises (per 100,000 inhabitants, logarithmic scale). The variables Mafia $\times(t+\tau)$ are interaction terms of Mafia - an indicator variable taking the value of one for provinces within the third tertile of the TMI distribution - with indicator variables for each year. Period $t$ identifies the starting year of the subprime mortgage crisis and the red vertical dashed line visually separates the pre-crisis and the post-crisis periods. The model is the complete model (see text for further details) and includes province fixed effects, year fixed effects, macro region-year fixed effects, and the set of control variables described in Section 3.1. The figure reports each point estimate of Mafia $\times(t+\tau)$ for the effect of mafia presence in a specific year together with the $90 \%$ (black), $95 \%$ (gray) and $99 \%$ (light gray) confidence intervals. Confidence intervals are based on spatially $(200 \mathrm{~km})$ and serially (11 years) correlated standard errors. 
Figure 6: Validation, Placebo, and Falsification Tests
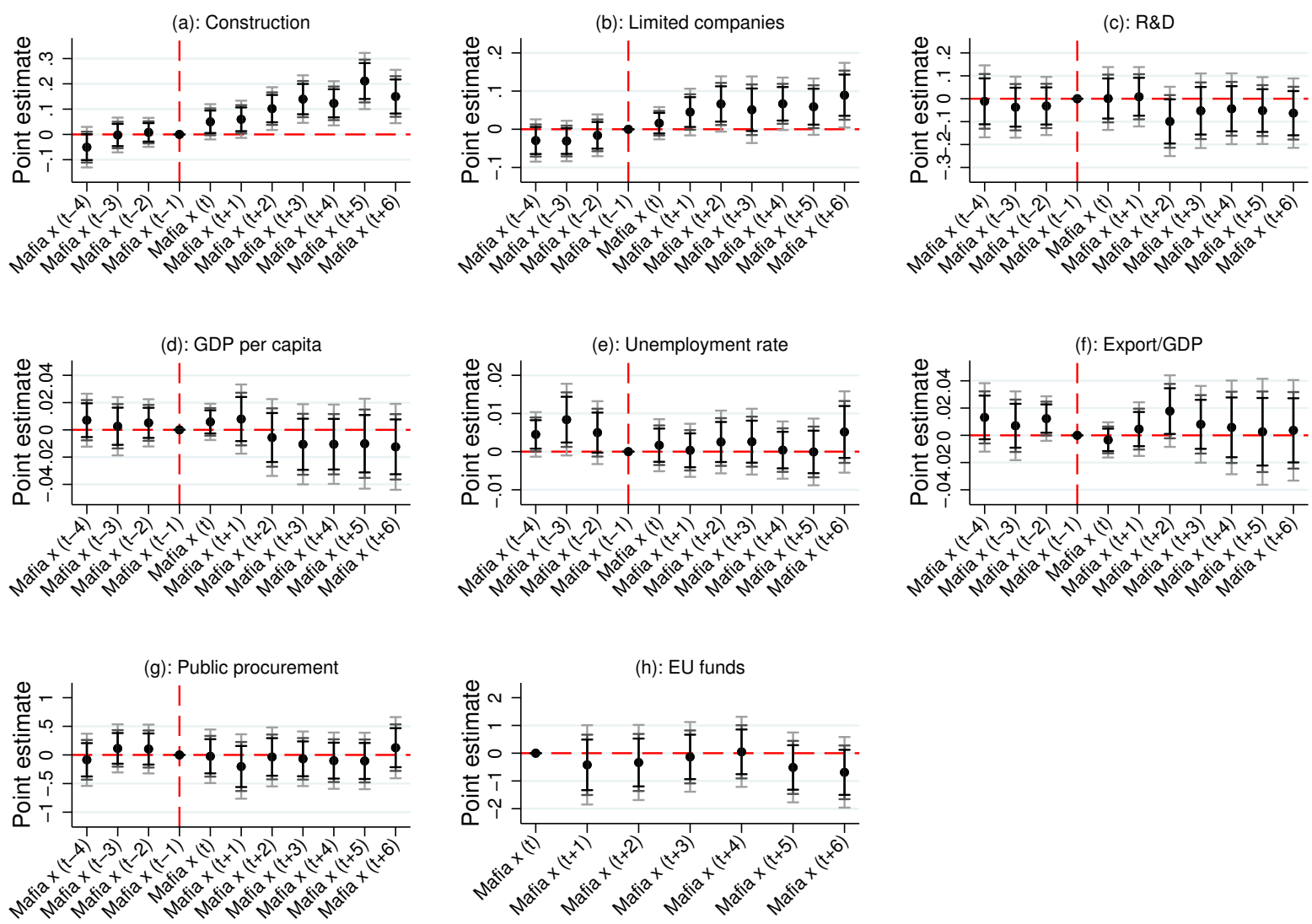

Note: This figure shows the validation, placebo, and falsification tests for the baseline analysis. The dependent variables are the number of new enterprises in the construction sector (per 100,000 inhabitants, logarithmic scale, figure (a)), the number of new enterprises with legal form of limited company (per 100,000 inhabitants, logarithmic scale, figure (b)), the number of new enterprises in the R\&D sector (per 100,000 inhabitants, logarithmic scale, figure (c)), GDP per capita (figure (d)), unemployment rate (figure (e)), exports over GDP (figure (f)), the amount of public procurement (per 100,000 inhabitants, logarithmic scale, figure $(\mathrm{g})$ ), and the amount of EU funds (per 100,000 inhabitants, logarithmic scale, figure (h)). The variables Mafia $\times(t+\tau)$ are interaction terms of Mafia - an indicator variable taking the value of one for provinces within the third tertile of the TMI distribution - with indicator variables for each year. Period $t$ identifies the starting year of the subprime mortgage crisis and the red vertical dashed line visually separates the pre-crisis and the post-crisis periods. Data on EU funds are only available after period $t$. The model is the complete model (see text for further details) and includes province fixed effects, year fixed effects, macro region-year fixed effects, and the set of control variables described in Section 3.1. All figures report each point estimate of Mafia $\times(t+\tau)$ for the effect of mafia presence in a specific year together with the 90\% (black), 95\% (gray) and $99 \%$ (light gray) confidence intervals. Confidence intervals are based on spatially (200 km) and serially (11 years) correlated standard errors. 
Table 1: Mafia Presence and Credit Contraction

(1)

(2)

Change credit Change credit

\begin{tabular}{|c|c|c|}
\hline Mafia $\times$ Crisis & $\begin{array}{c}0.013 \\
(0.008)\end{array}$ & \\
\hline Mafia × 2004 & & $\begin{array}{l}-0.006 \\
(0.014)\end{array}$ \\
\hline Mafia $\times 2005$ & & $\begin{array}{l}-0.006 \\
(0.011)\end{array}$ \\
\hline Mafia $\times 2007$ & & $\begin{array}{c}0.007 \\
(0.017)\end{array}$ \\
\hline Mafia × 2008 & & $\begin{array}{c}0.022 \\
(0.021)\end{array}$ \\
\hline Mafia × 2009 & & $\begin{array}{c}0.012 \\
(0.016)\end{array}$ \\
\hline Mafia × 2010 & & $\begin{array}{c}0.001 \\
(0.015)\end{array}$ \\
\hline Mafia × 2011 & & $\begin{array}{c}0.021 \\
(0.014)\end{array}$ \\
\hline Mafia × 2012 & & $\begin{array}{c}0.002 \\
(0.012)\end{array}$ \\
\hline Mafia × 2013 & & $\begin{array}{l}-0.003 \\
(0.014)\end{array}$ \\
\hline Observations & 840 & 840 \\
\hline$R^{2}$ & 0.616 & 0.620 \\
\hline Province FE & YES & YES \\
\hline Year FE & YES & YES \\
\hline
\end{tabular}

Note: This table shows the analysis of the differential effect of the credit contraction induced by the subprime mortgage crisis in provinces with and without mafia presence. The dependent variable is the rate of change with respect to the previous year in the amount of credit provided to the entrepreneurial system. In column (1), the variable Mafia $\times$ Crisis is the interaction of Mafia - an indicator variable taking the value of one for provinces within the third tertile of the TMI distribution - with an indicator variable for the post-crisis period. In column (2), the variables Mafia $\times$ Year are interaction terms of Mafia with indicator variables for each year. The interaction of Mafia with the indicator variable for the year 2006, the last year of the pre-crisis period, is the reference category for the analysis in column (2). Standard errors are clustered at the provincial level. *, **,*** indicate statistical significance at the $10 \%, 5 \%$, and $1 \%$ levels, respectively. 
Table 2: Balancing Tests

\begin{tabular}{|c|c|c|c|}
\hline & $\begin{array}{c}(1) \\
\text { Mean } \\
\text { No Mafia }\end{array}$ & $\begin{array}{c}(2) \\
\text { Mean } \\
\text { Mafia }\end{array}$ & Difference \\
\hline Big banks (\%) & 0.329 & 0.404 & $-0.074^{* *}$ \\
\hline Self-employed (\%) & 0.285 & 0.269 & $0.016^{*}$ \\
\hline Tourism index & 3.361 & 2.098 & 1.264 \\
\hline Wastes per capita (tons) & 0.551 & 0.562 & -0.011 \\
\hline Trial duration (days) & 3048 & 3083 & -35 \\
\hline Urban population (\%) & 0.255 & 0.294 & -0.039 \\
\hline Newspaper circulation (1,000 inh.) & 122 & 115 & 7 \\
\hline Blood donations (bags per 100 inh.) & 3.810 & 3.148 & 0.662 \\
\hline
\end{tabular}

Note: This table shows the comparison of a set of observable characteristics between provinces without and with mafia presence. The table reports, for each characteristic, the average value over the pre-crisis period for the group of provinces without mafia presence (first and second tertiles of the TMI distribution) in column (1) and with mafia presence (third tertile of the TMI distribution) in column (2). The sample includes 84 Italian provinces, 56 without mafia presence and 28 with mafia presence. Column (3) reports the difference between columns (1) and (2) and the statistical significance of the difference in means between the two groups of provinces. $*, * *, * * *$ indicate statistical significance at the $10 \%, 5 \%$ and $1 \%$ levels, respectively. 
Table 3: Mafia Presence and New Enterprises

\begin{tabular}{lccccc}
\hline & $\begin{array}{c}(1) \\
\text { New } \\
\text { enterprises }\end{array}$ & $\begin{array}{c}(2) \\
\text { New } \\
\text { enterprises }\end{array}$ & $\begin{array}{c}\text { New } \\
\text { enterprises }\end{array}$ & $\begin{array}{c}\text { New } \\
\text { enterprises }\end{array}$ & $\begin{array}{c}(5) \\
\text { New } \\
\text { enterprises }\end{array}$ \\
\hline Mafia $\times$ Crisis & $0.038^{*}$ & $0.038^{* *}$ & $0.034^{* * *}$ & $0.039^{* * *}$ & $0.039^{* * *}$ \\
& $(0.020)$ & $(0.017)$ & $(0.013)$ & $(0.013)$ & $(0.011)$ \\
Observations & 924 & 924 & 924 & 924 & 924 \\
$R^{2}$ & 0.011 & 0.017 & 0.215 & 0.350 & 0.413 \\
Province FE & YES & YES & YES & YES & YES \\
Year FE & NO & YES & YES & YES & YES \\
North $\times$ Years FE & NO & NO & YES & NO & YES \\
Controls & NO & NO & NO & YES & YES \\
\hline
\end{tabular}

Note: This table shows the effect of mafia presence on established enterprises in the post-crisis period. The dependent variable is the number of new enterprises (per 100,000 inhabitants, logarithmic scale). The variable Mafia $\times$ Crisis is the interaction of Mafia - an indicator variable taking the value of one for provinces within the third tertile of the TMI distribution - with an indicator variable for the post-crisis period. The set of controls includes variables for the number of big banks, the importance of self-employment, the capacity to attract tourism, waste per capita, trial duration, urban population, newspaper circulation, and blood donations. See Section 3.1 for further details on control variables. Standard errors are adjusted for spatial $(200 \mathrm{~km})$ and serial (11 years) correlation. *, **, *** indicate statistical significance at the $10 \%, 5 \%$, and $1 \%$ levels, respectively. 


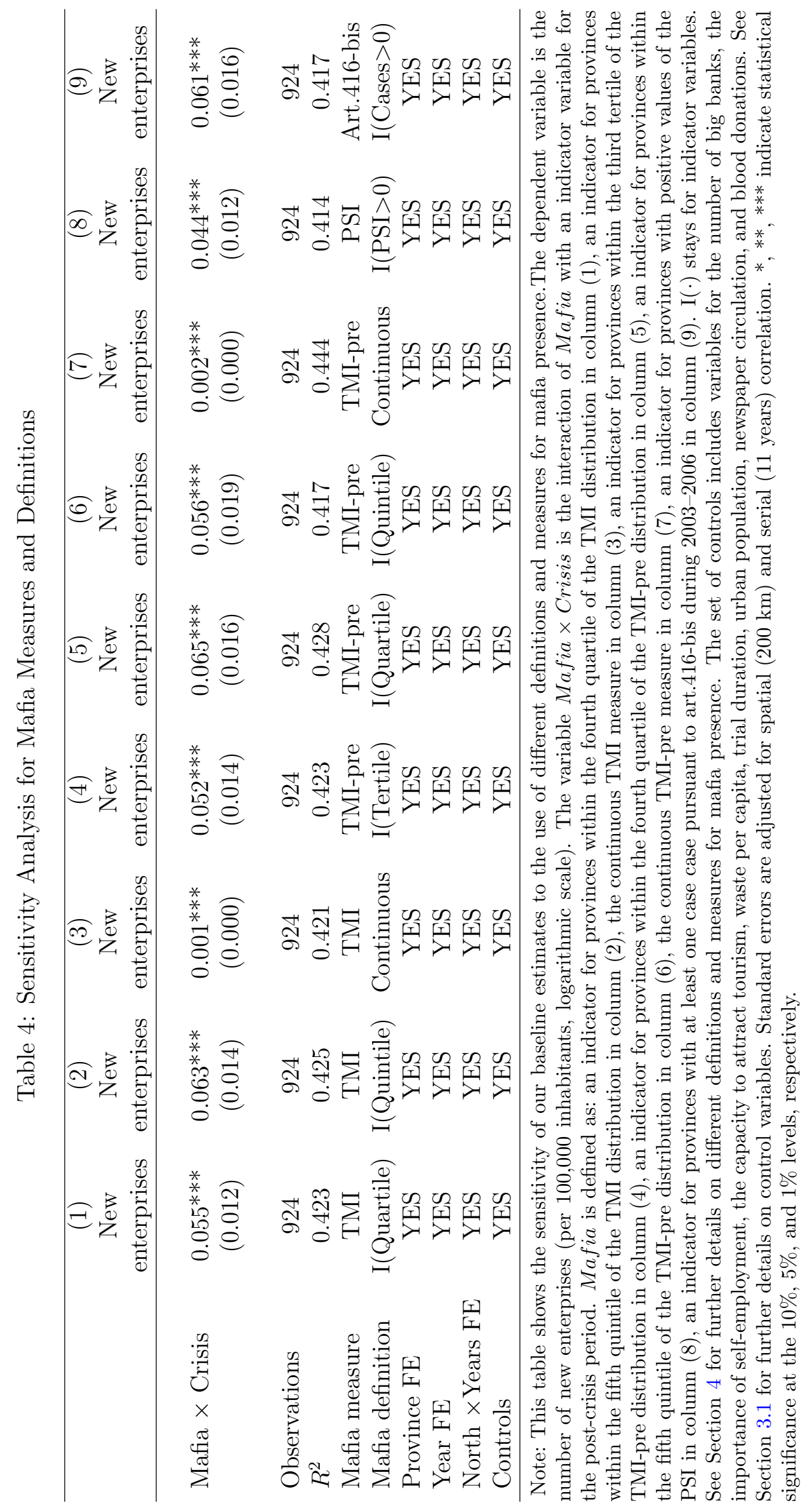


Table 5: Robustness I: Sample Selection

\begin{tabular}{lcc}
\hline & $\begin{array}{c}(1) \\
\text { New } \\
\text { enterprises }\end{array}$ & $\begin{array}{c}(2) \\
\text { New } \\
\text { enterprises }\end{array}$ \\
\hline Mafia $\times$ Crisis & $\begin{array}{c}0.053^{* * *} \\
(0.012)\end{array}$ & $\begin{array}{c}0.024^{* *} \\
(0.010)\end{array}$ \\
& & \\
Observations & 1,133 & 869 \\
$R^{2}$ & 0.386 & 0.371 \\
Sample & All regions & Exclusion Apulia \\
Province FE & YES & YES \\
Year FE & YES & YES \\
NorthXYears FE & YES & YES \\
Controls & YES & YES \\
\hline
\end{tabular}

Note: This table shows the robustness test for sample selection. The dependent variable is the number of new enterprises (per 100,000 inhabitants, logarithmic scale). The variable Mafia $\times$ Crisis is the interaction of Mafia-an indicator variable taking the value of one for provinces within the third tertile of the TMI distribution - with an indicator variable for the post-crisis period. In column (1) the sample includes all Italian regions. In column (2) the sample excludes the Apulia region in addiction to the three regions excluded from the baseline analysis, namely Sicily, Campania, and Calabria. The set of controls includes variables for the number of big banks, the importance of self-employment, the capacity to attract tourism, waste per capita, trial duration, urban population, newspaper circulation, and blood donations. See Section 3.1 for further details on control variables. Standard errors are adjusted for spatial $(200 \mathrm{~km})$ and serial (11 years) correlation. ${ }^{*}, * *, * * *$ indicate statistical significance at the $10 \%, 5 \%$, and $1 \%$ levels, respectively. 
Table 6: Robustness II: Trends for Control Variables

\begin{tabular}{lcccc}
\hline & $(1)$ & $(2)$ & $(3)$ & $(4)$ \\
& $\begin{array}{c}\text { New } \\
\text { enterprises }\end{array}$ & $\begin{array}{c}\text { New } \\
\text { enterprises }\end{array}$ & $\begin{array}{c}\text { New } \\
\text { enterprises }\end{array}$ & $\begin{array}{c}\text { New } \\
\text { enterprises }\end{array}$ \\
\hline Mafia $\times$ Crisis & $0.035^{* * *}$ & $0.036^{* * *}$ & $0.025^{* * *}$ & $0.024^{* *}$ \\
& $(0.011)$ & $(0.011)$ & $(0.009)$ & $(0.010)$ \\
Observations & 924 & 924 & & 924 \\
$R^{2}$ & 0.418 & 0.453 & 0.473 & 0.516 \\
Trends & Credit market & Economic & Institut.-social & All \\
& structure & environment & environment & \\
Province FE & YES & YES & YES & YES \\
Year FE & YES & YES & YES & YES \\
North $\times$ Years FE & YES & YES & YES & YES \\
Controls & YES & YES & YES & YES \\
\hline
\end{tabular}

Note: This table shows the robustness test based on the inclusion in the model of trends for control variables. The dependent variable is the number of new enterprises (per 100,000 inhabitants, logarithmic scale). The variable Mafia $\times$ Crisis is the interaction of Mafia - an indicator variable taking the value of one for provinces within the third tertile of the TMI distribution - with an indicator variable for the post-crisis period. In column (1) we include interactions between the control variable for the credit market structure (big banks) and indicator variables for each year. In column (2) we include interactions between the control variables for the economic environment (self-employment, tourism, and waste) and indicator variables for each year. In column (3) we include interactions between the control variables for the institutional and social environment (trial duration, urban population, newspaper circulation, and blood donation) and indicator variables for each year. In column (4) we include interactions between all the control variables and indicator variables for each year. In all columns we interact predetermined values - values observed in period $t-1$ - for each control variable with an indicator variable for each year. The set of controls includes variables for the number of big banks, the importance of self-employment, the capacity to attract tourism, waste per capita, trial duration, urban population, newspaper circulation, and blood donations. See Section 3.1 for further details on control variables. Standard errors are adjusted for spatial $(200 \mathrm{~km})$ and serial (11 years) correlation. $*$, **, *** indicate statistical significance at the $10 \%, 5 \%$, and $1 \%$ levels, respectively. 
Table 7: Robustness III: Financial Resources

\begin{tabular}{lcc}
\hline & $\begin{array}{c}(1) \\
\text { New } \\
\text { enterprises }\end{array}$ & $\begin{array}{c}(2) \\
\text { New } \\
\text { enterprises }\end{array}$ \\
\hline Mafia $\times$ Crisis & $0.038^{* * *}$ & $0.031^{* * *}$ \\
& $(0.011)$ & $(0.011)$ \\
Observations & 924 & 924 \\
$R^{2}$ & 0.415 & 0.445 \\
Additional controls & DSP $\times$ Years & Credit \\
Province FE & YES & YES \\
Year FE & YES & YES \\
North $\times$ Years FE & YES & YES \\
Controls & YES & YES \\
\hline
\end{tabular}

Note: This table shows the robustness test based on the inclusion in the model of additional controls for financial resources available to entrepreneurs. The dependent variable is the number of new enterprises (per 100,000 inhabitants, logarithmic scale). The variable Mafia $\times$ Crisis is the interaction of Mafia - an indicator variable taking the value of one for provinces within the third tertile of the TMI distribution - with an indicator variable for the postcrisis period. In column (1) we include the interaction of the fraction of municipalities under DSP in each province with indicator variables for each year. In column (2) we include the control for the amount of credit granted to the entrepreneurial system at the province-year level. The set of controls includes variables for the number of big banks, the importance of self-employment, the capacity to attract tourism, waste per capita, trial duration, urban population, newspaper circulation, and blood donations. See Section 3.1 for further details on control variables. Standard errors are adjusted for spatial $(200 \mathrm{~km})$ and serial (11 years) correlation. *, **, *** indicate statistical significance at the $10 \%, 5 \%$, and $1 \%$ levels, respectively. 
Table 8: Robustness IV: Instrumental Variables

\begin{tabular}{|c|c|c|c|c|c|}
\hline & $\begin{array}{c}\text { (1) } \\
\text { New } \\
\text { enterprises }\end{array}$ & $\begin{array}{c}(2) \\
\text { New } \\
\text { enterprises }\end{array}$ & $\begin{array}{c}\text { (3) } \\
\text { New } \\
\text { enterprises }\end{array}$ & $\begin{array}{c}\text { (4) } \\
\text { New } \\
\text { enterprises }\end{array}$ & $\begin{array}{c}\text { (5) } \\
\text { New } \\
\text { enterprises }\end{array}$ \\
\hline \multirow[t]{2}{*}{ Mafia $\times$ Crisis } & $\begin{array}{c}0.079 \\
(0.103)\end{array}$ & $\begin{array}{c}0.079 \\
(0.103)\end{array}$ & $\begin{array}{c}0.050 \\
(0.089)\end{array}$ & $\begin{array}{c}0.119^{* *} \\
(0.058)\end{array}$ & $\begin{array}{c}0.118^{* *} \\
(0.055)\end{array}$ \\
\hline & \multicolumn{5}{|c|}{ First-stage estimates } \\
\hline Resettled $\times$ Crisis & $\begin{array}{c}0.007^{* * * *} \\
(0.003)\end{array}$ & $\begin{array}{c}0.007^{* * *} \\
(0.003)\end{array}$ & $\begin{array}{c}0.007^{* * *} \\
(0.003)\end{array}$ & $\begin{array}{c}0.007^{* * * *} \\
(0.002)\end{array}$ & $\begin{array}{c}0.007^{* * *} \\
(0.002)\end{array}$ \\
\hline K-P Wald F statistic & 8.187 & 8.187 & 8.372 & 8.955 & 8.764 \\
\hline Observations & 847 & 847 & 847 & 847 & 847 \\
\hline$R^{2}$ & 0.770 & 0.851 & 0.885 & 0.894 & 0.906 \\
\hline Province FE & YES & YES & YES & YES & YES \\
\hline Year FE & $\mathrm{NO}$ & YES & YES & YES & YES \\
\hline North $\times$ Years FE & $\mathrm{NO}$ & $\mathrm{NO}$ & YES & $\mathrm{NO}$ & YES \\
\hline Controls & $\mathrm{NO}$ & $\mathrm{NO}$ & $\mathrm{NO}$ & YES & YES \\
\hline
\end{tabular}

Note: This table shows the robustness test based on the IV analysis. The dependent variable is the number of new enterprises (per 100,000 inhabitants, logarithmic scale). The variable Mafia $\times$ Crisis is the interaction of Mafia - an indicator variable taking the value of one for provinces within the third tertile of the TMI distribution - with an indicator variable for the post-crisis period. The first-stage dependent variable is Mafia $\times$ Crisis. The external instrument Resettled $\times$ Crisis is the interaction of Crisis with Resettled, the total number of mafia members resettled to each province during 1961-1974. The set of controls includes variables for the number of big banks, the importance of self-employment, the capacity to attract tourism, waste per capita, trial duration, urban population, newspaper circulation, and blood donations. See Section 3.1 for further details on control variables. Standard errors are adjusted for spatial $(200 \mathrm{~km})$ and serial (11 years) correlation. $*, * *, * * *$ indicate statistical significance at the $10 \%, 5 \%$, and $1 \%$ levels, respectively. 
Table 9: Mafia Presence, Closed, and Registered Enterprises

(1)

Closed enterprises Registered enterprises

\begin{tabular}{lcc} 
Mafia $\times$ Crisis & 0.026 & 0.014 \\
& $(0.018)$ & $(0.009)$ \\
& & \\
Observations & 924 & 924 \\
$R^{2}$ & 0.181 & 0.512 \\
Province FE & YES & YES \\
Year FE & YES & YES \\
North $\times$ Years FE & YES & YES \\
Controls & YES & YES \\
\hline
\end{tabular}

Note: This table shows the effect of mafia presence on closed and registered enterprises in the post-crisis period. The dependent variables are the number of closed enterprises in column (1) and the number of registered enterprises in column (2). Both dependent variables are expressed as the logarithm of the number of enterprises per 100,000 inhabitants. The variable Mafia $\times$ Crisis is the interaction of Mafia - an indicator variable taking the value of one for provinces within the third tertile of the TMI distribution - with an indicator variable for the post-crisis period. The set of controls includes variables for the number of big banks, the importance of self-employment, the capacity to attract tourism, waste per capita, trial duration, urban population, newspaper circulation, and blood donations. See Section 3.1 for further details on control variables. Standard errors are adjusted for spatial $(200 \mathrm{~km})$ and serial (11 years) correlation. ${ }^{*}, * *, * * *$ indicate statistical significance at the $10 \%, 5 \%$, and $1 \%$ levels, respectively. respectively. 


\section{Appendix}

\section{A.1 Data Sources}

The following list describes all the variables used in our analysis with their source(s).

- Number of New Enterprises: number of new enterprises per 100,000 inhabitants set up each year at the provincial level. The data are collected by the Italian National Institute of Statistics (ISTAT), which makes publicly available only the number of new enterprises at the provincial level without additional information such as enterprise name and size.

- Number of New Enterprises - Construction sector: number of new enterprises in the construction sector per 100,000 inhabitants set up each year at the provincial level. The construction industry is labeled as F in the Ateco 2002 and the Ateco 2007 classifications. The data are collected by the Italian Chamber of Commerce.

- Number of New Enterprise - R\&D sector: number of new enterprises in the sector of professional, scientific, and technical activities (per 100,000 inhabitants) set up each year at the provincial level. Professional, scientific, and technical activities are labeled as M in the Ateco 2002 and the Ateco 2007 classifications. The data are collected by the Italian Chamber of Commerce.

- Number of New Enterprises - Limited companies: number of new enterprises registered as a limited company per 100,000 inhabitants set up each year at the provincial level. Limited companies include the so-called "Società a Responsabilità Limitata." The data are collected by the Italian Chamber of Commerce.

- Number of Closed Enterprises: number of enterprises per 100,000 inhabitants closed each year at the provincial level. The data are collected by the Italian National Institute of Statistics (ISTAT), which makes publicly available only the number of closed enterprises at the provincial level without additional information such as enterprise name and size. 
- Number of Registered Enterprises: stock of registered enterprises per 100,000 inhabitants each year at the provincial level. The data are collected by the Italian National Institute of Statistics (ISTAT), which makes publicly available only the number of registered enterprises at the provincial level without additional information such as enterprise name and size.

- Big Banks: percentage of big banks at the year-province level. The Bank of Italy defines big banks as those with a total value of traded funds greater than $€ 26$ billion. The data are collected by the Bank of Italy.

- Self-Employment: percentage of the population that is self-employed over the total number of employed people in each province. The data are collected by the Italian National Institute of Statistics (ISTAT).

- Tourism: index of the capacity of a given province to attract tourism-type consumption in a specific year in terms of days spent by tourists within a province per inhabitant. The data are collected by the Italian National Institute of Statistics (ISTAT).

- Waste: per capita number of tons of waste produced at the province-year level. The data are collected by the research center Istituto Superiore per la Protezione e Ricerca Ambientale (ISPRA).

- Trial Duration: average length in days of a trial for bankruptcy at the province-year level. Data are available for 2000-2007. For following years, we impute the average provincial values over the eight preceding years (e.g. for 2008 we computed the average between 2000 and 2007). The data are collected by the Italian National Institute of Statistics (ISTAT).

- Urban Population: percentage of urban population over the total provincial population at the province-year level. The data are collected by the Italian National Institute of Statistics (ISTAT).

- Newspaper Circulation: total number of newspapers sold (per 1,000 inhabitants) at the year-province level. The data are collected by the Italian National Press Agency 
(Accertamenti Diffusione Stampa - ADS).

- Blood Donations: number of blood bags per 100 inhabitants at the year-regional level. The data are collected by the Italian National Agency for Blood Donation (Agenzia Volontari Italiani del Sangue - AVIS).

- GDP per capita: gross domestic product per capita at current market price at provinceyear level. The data are collected by Eurostat.

- Unemployment rate: number of unemployed persons as percentage of the labor force at province-year level. The labor force includes unemployed individuals plus those in paid or self-employment. The data are collected by the Italian National Institute of Statistics (ISTAT).

- Export/GDP: share of the total amount of exports with respect to the GDP at the province-year level. Data on exports are collected by the Italian National Institute of Statistics (ISTAT).

- Public procurement: total amount of public procurement at the province-year level per 100,000 inhabitants. The data contain the universe of public procurement contracts for projects above EUR 40,000. The data are elaborated by De Carolis et al. (2019) from records of the Italian National Anticorruption Authority (ANAC).

- EU funds: total amount of funds at the province-year level made available under the EU multi-year budget for 2007-2013. The data are collected by OpenCoesione.

- Resettled: total number of people resettled from Sicily, Campania, and Calabria across Italian provinces during 1961-1974 under the confino law. For each of the provinces outside the three regions of original mafia, we compute the total number of mafia members hosted following the application of the 1956 law. The data to construct the variable are provided by the Antimafia Commission of the Parliament, and in particular, from its 1976 annual report. 


\section{A.2 The Transcrime Mafia Index}

The Transcrime Mafia Index (TMI) is provided by Transcrime, an Italian research center on transnational crime. The construction of the index is based on the work of Calderoni (2011). The version of the index employed in this paper is the one provided in the report "Mafia Investments" funded by the Italian Ministry of Internal Affairs and the European Union (Ministry of the Interior, 2013). The TMI defines mafia as a "system characterized by the presence of criminal groups providing illicit goods and services; using violence, threat, or intimidation to pursue their aims; and with a high degree of infiltration in the political and the economic system." According to the TMI, a mafia-type organization is characterized by four main features:

- Presence of criminal groups providing illegal goods and services;

- Use of violence, threat, or intimidation to pursue its aims;

- Infiltration into the political system;

- Infiltration into the economic system.

These four features are approximated by using four different types of criminal activities and criminal records as specific markers for them. In particular, the type of criminal records taken into account are:

- Mafia-type association as described in Law 646 (art.416-bis). Mafia-type association is defined as "a group of people that by use of intimidating behavior, membership to the organization subjugation, and a code of silence, commit criminal activities to acquire direct or indirect control of economic activities, concessions, authorizations, public contracts, or to generate illicit profits or advantages or to impede or obstruct the exercise of the right to vote or to ensure the procurement of votes for them or for others during elections." The data are provided for 2004-2011 by the Ministry of the Interior (Sistemi D'Indagine - SDI);

- Murders committed by mafia members. The data are provided for 2004-2011 by the Ministry of the Interior (Sistemi D'Indagine - SDI); 
- City councils dissolved because of mafia infiltration. The data are provided for 20002011 by the Ministry of the Interior;

- Assets seized from organized crime. The data are provided for the period 2000-2011 by the Agenzia Nazionale per l'Amministrazione e la Destinazione dei Beni Sequestrati e Confiscati alla Criminalità Organizzata and Agenzia del Demanio.

All the records, with the exception of city councils dissolved because of mafia infiltration, are normalized per 10,000 inhabitants and averaged at the provincial level. Then, for each of the four features, a rank of the provinces is created and the following indexes are calculated for each province:

$$
\operatorname{Index}_{c, i}=\left[\operatorname{NormRec}_{c, i} / \operatorname{Max}\left(\operatorname{NormRec}_{c}\right)\right] * 1000
$$

In particular, the index for crime $c$ in province $i$ is equal to the ratio between the average number of records for crime $c$ in province $i$ and the highest average number of records for crime $c$ observed among all the Italian provinces. The final TMI score for each province is the average of the four indexes. For simplicity, the final score used in this paper has been rescaled to the $0-1$ interval. 


\section{A.3 The Subprime Mortgage Crisis}

In this appendix, we further discuss some features of the subprime mortgage crisis, one of the main elements of the identification strategy of this work. The aim of this section is to provide more detail and empirical evidence on some points touched on in the description of the empirical strategy in the main text.

As mentioned in the main text, we need the shock induced by the subprime mortgage crisis to induce a sizable and exogenous credit shock that affects the Italian credit market. The US-origin of the 2007 subprime mortgage crisis makes the credit shock unanticipated by the Italian credit market. The shock rapidly spread to the rest of the world. As noted by Jean-Claude Trichet, the President of the European Central Bank (ECB) in 2010: "[T]he difficulties experienced by a small number of investment funds in June 2007, owing to the non-performance of US subprime mortgage securities, led rating agencies to downgrade a large number of asset-backed instruments. The immediate consequence of these downgrades was a deterioration in the quality of the balance sheets of banks holding those securities, as their price fell and capital losses were incurred. As the number of large and complex financial institutions severely affected by the re-pricing of asset-backed securities was recognized, this financial shock was propagated to the broader financial market and real economy. The ensuing rounds of write-downs and a lack of transparency regarding exposures to these toxic instruments created an atmosphere of anxiety and suspicion (Trichet, 2010)."

Figure A.1 shows the difference between interbank interest rates-LIBOR for United States and EURIBOR for the European Union - and the interest rate on the equivalent index swap rate. The spread between the interbank interest rate and the index swap rate is negligible up to the second half of 2007 , when it suddenly starts to rapidly increase.

In Figure A.2, we show the diffusion index for the general supply of credit in Italy during the analysis period of this work, i.e. 2003-2013. The diffusion index reflects the weighted differences between the share of banks reporting that credit standards have been tightened and the share of banks reporting that credit standards have been eased. The index is produced by the ECB using the information contained in the Bank Lending Survey (BLS). The survey, run since 2003 by the Bank of Italy in collaboration with the ECB, asks senior loan officers respon- 
Figure A.1: Interbank Market Spread

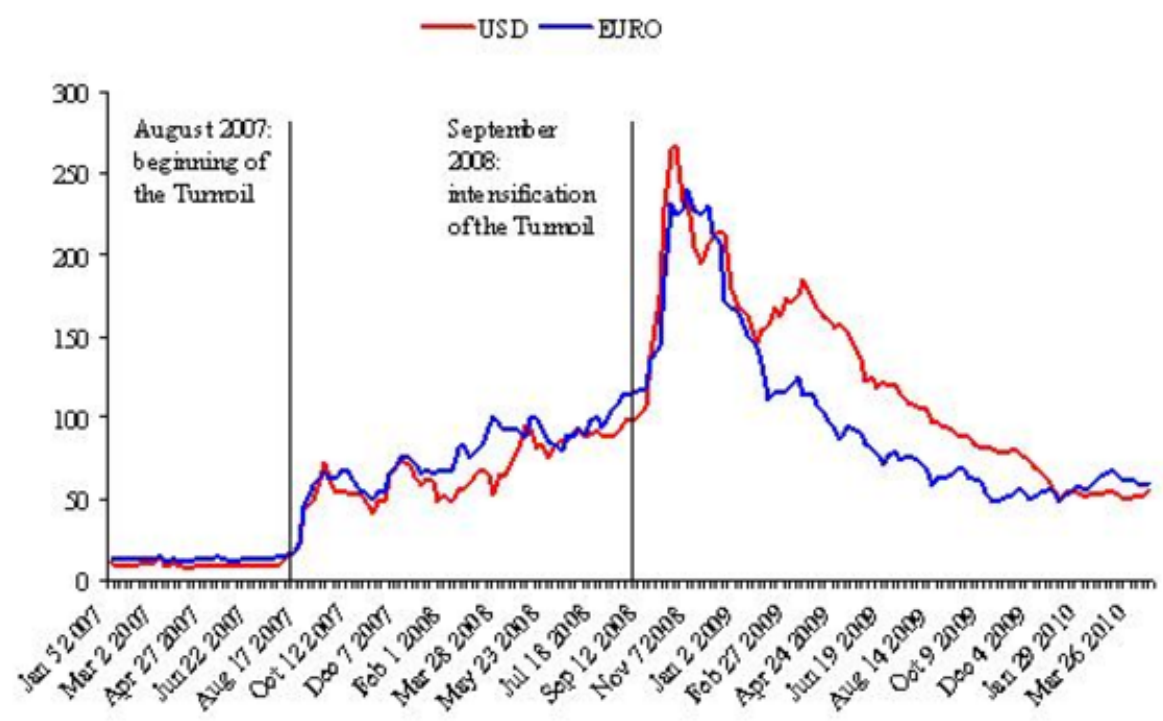

Note: This figure shows the difference between 12-month EURIBOR (blue line), LIBOR (red line), and Overnight Index Swap rates, in basis points. The figure is based on Reuters/Haver Analytics and ECB calculations.

sible for credit policies of the main banks of the euro area (around 150, with ten representing the major Italian banks) to express their opinions on the relative importance of demand and supply factors in explaining lending patterns. This information is then summarized by the diffusion index. See www.ecb.europa.eu/stats/money/surveys/lend/html/index.en.html for further details about the index.

The original index varies between minus one, which is all banks reporting easing lending standards, and one, which is all banks reporting tightening lending standards. To make its interpretation easier, in Figure A.2 we reverted the sign of the original index, with positive (negative) values indicating easing (tightening) in bank lending standards. As reported in the main text, Italian loan officers reported a tightening of the lending standards almost contemporaneous to the beginning of the financial turmoil in the United States in 2007. 
Figure A.2: The Diffusion Index

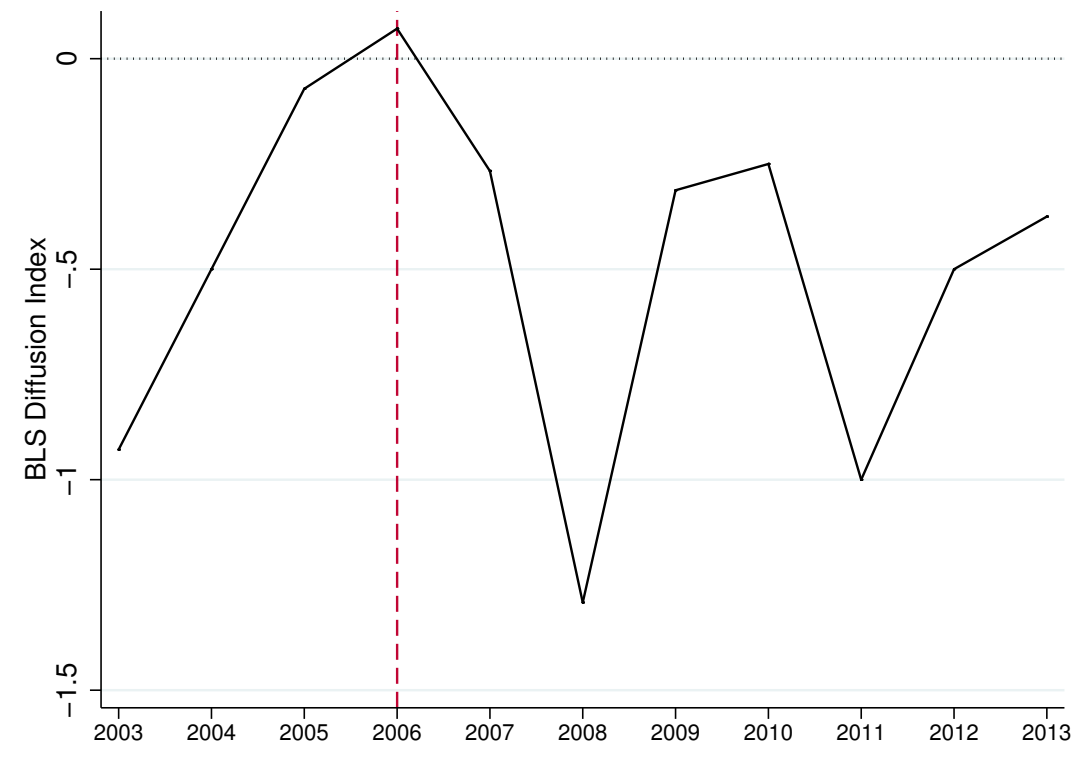

Note: This figure shows the BLS diffusion index for the general supply of credit in Italy during 2003-2013. Positive (negative) values of the diffusion index indicate easing (tightening) in bank lending standards. The figure is based on the authors' calculations on data from the BLS and Bank of Italy. Refer to the text for further details. 


\section{A.4 Measuring Mafia Presence: The Power Syndicate Index}

The Power Syndicate Index (PSI) is recovered from the report "Alleanze nell'ombra. Mafie ed economie locali in Sicilia e nel Mezzogiorno" produced by Fondazione RES. The PSI defines a set of illicit activities undertaken to gain territorial control. These activities include mafia-type association as described in Law 646 (art.416-bis), murders committed by mafia members, and racketeering practices. Mafia-type association is defined as "a group of people that by use of intimidating behavior, membership to the organization subjugation and a code of silence, commit criminal activities, to acquire direct or indirect control of economic activities, concessions, authorizations, public contracts or to generate illicit profits or advantages or to impede, obstruct the exercise of the right to vote or to ensure the procurement of votes for them or for others during elections."

For all the core activities, records over 2004-2007 are used to compute the average number of cases and the crime rate per 100,000 inhabitants at both the provincial and the whole country level. These measures are then used to classify provinces along a four-point scale according to the following rule:

- Index =0: All core activities are smaller than the country's average level;

- Index $=1$ : At least one core activity is greater than the country's average level;

- Index $=2$ : At least two core activities are greater than the country's average level;

- Index $=3:$ All the core activities are greater than the country's average level. 


\section{A.5 Additional Figures}

Figure A.3: 2nd vs 1st Tertile of the TMI Distribution and New Enterprises

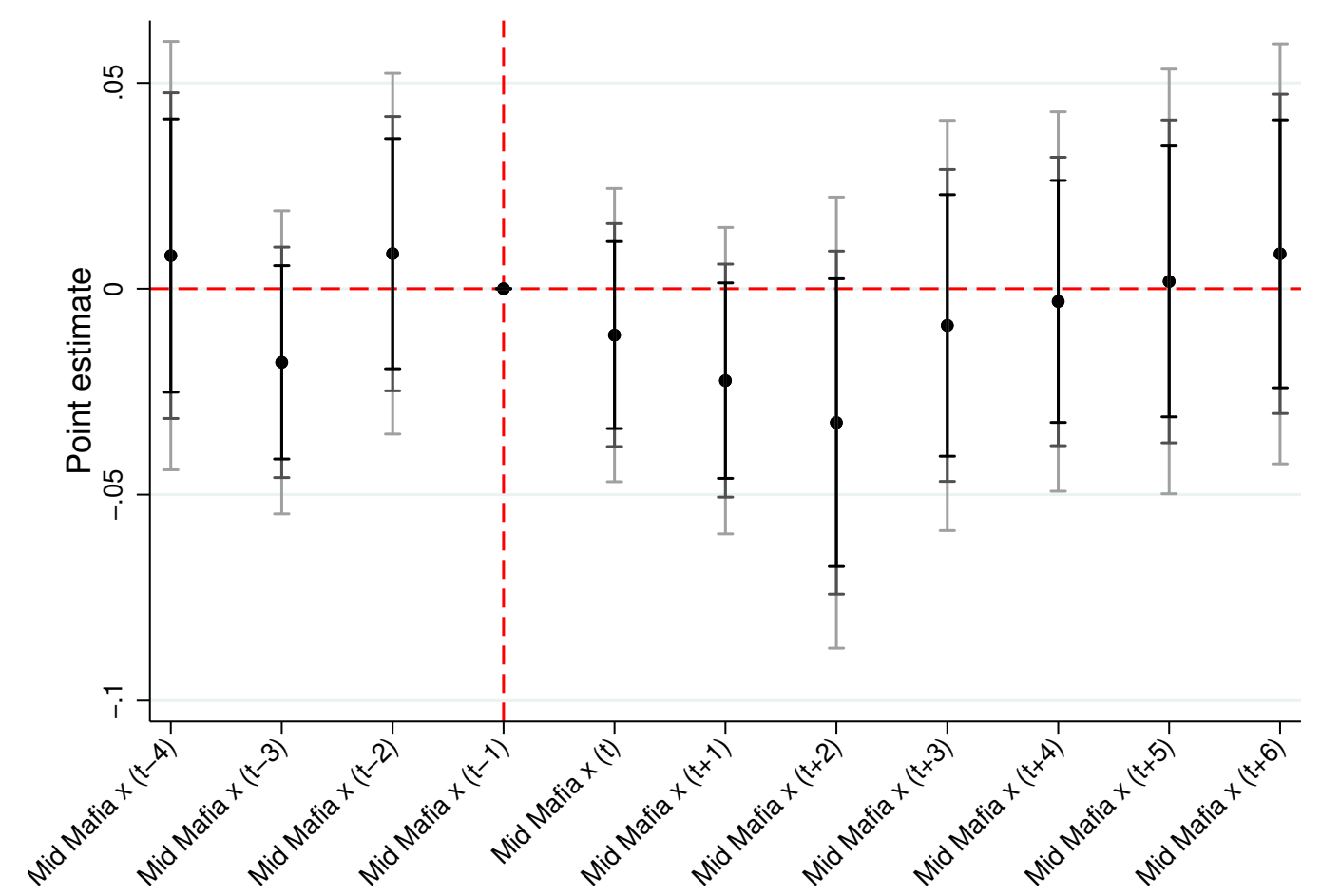

Note: This figure shows the effect the second versus the first tertile of the the TMI distribution on established enterprises. The dependent variable is the number of new enterprises (per 100,000 inhabitants, logarithmic scale). The variables MidMafia $\times(t+\tau)$ are interaction terms of MidMafia - an indicator variable taking the value of one for provinces within the second tertile of the TMI distribution and zero for provinces within the first tertile of the TMI distribution - with an indicator variable for each year. The year $t$ identifies the starting year of the subprime mortgage crisis and the red vertical dashed line visually separates the pre-crisis and the post-crisis periods. The model includes province fixed effects, year fixed effects, macro region-year fixed effects, and a set of controls variables for the number of big banks, the importance of self-employment, the capacity to attract tourism, waste per capita, trial duration, urban population, newspaper circulation, and blood donations. The figure reports each point estimate of MidMafia $\times(t+\tau)$ together with the $90 \%$ (black), 95\% (gray) and 99\% (light gray) confidence intervals. Confidence intervals are based on spatially $(200 \mathrm{~km})$ and serially (11 years) correlated standard errors. 
Figure A.4: Control Variables and New Enterprises - Event Study
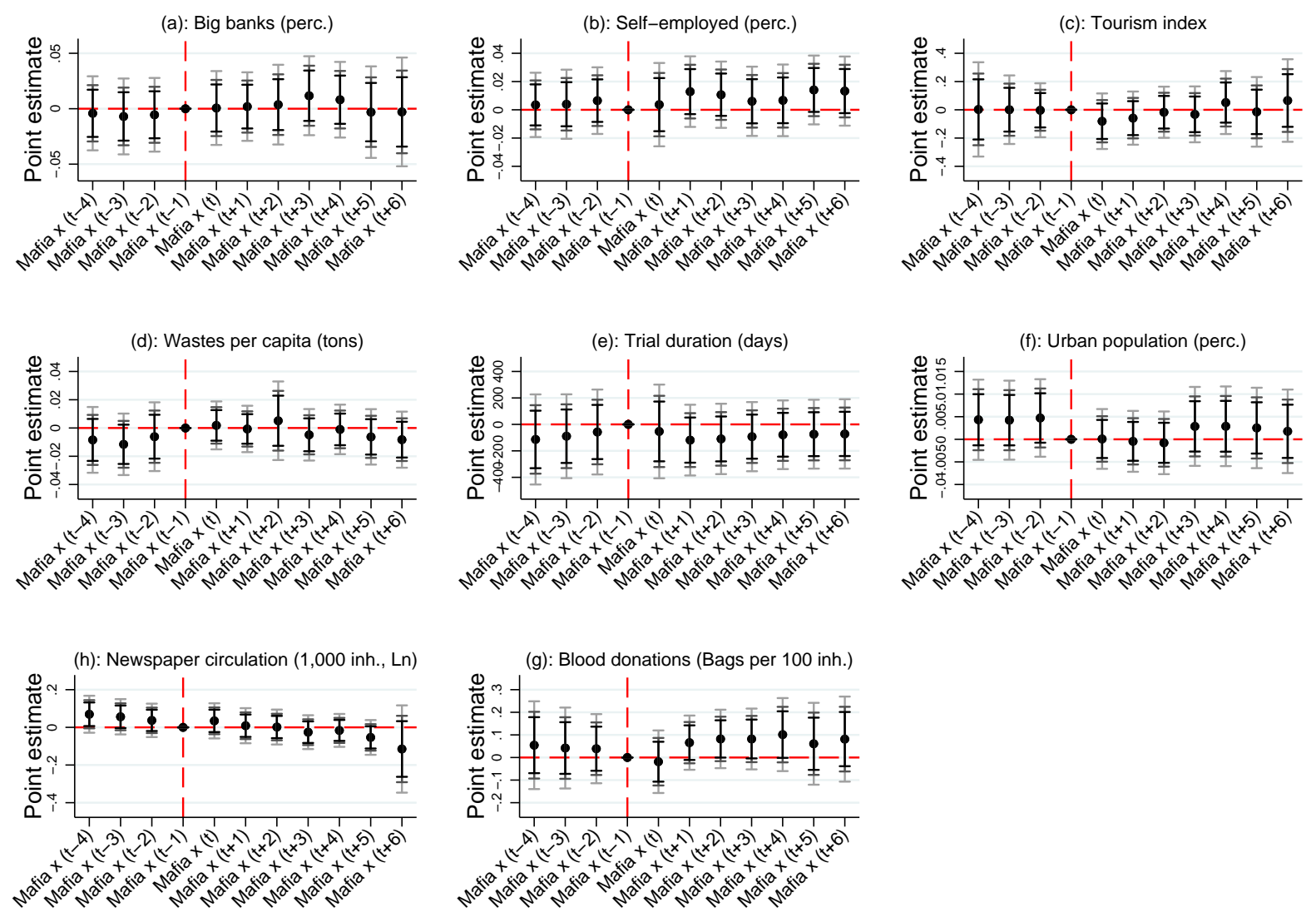

Note: This figure shows the evolution over time of the effect of mafia presence on each control variables used in the baseline analysis. The dependent variables are the number of big banks (\%, figure (a)), the importance of self-employment (\%, figure (b)), the capacity to attract tourism (index, figure (c)), waste per capita (tons, figure (d)), trial duration (days, figure (e)), urban population (\%, figure (f)), newspaper circulation (1,000 inh., figure $(\mathrm{g})$ ), and blood donations (bags per $100 \mathrm{inh}$., figure (h)). The variables Mafia $\times(t+\tau)$ are interaction terms of Mafia - an indicator variable taking the value of one for provinces within the third tertile of the TMI distribution - with indicator variables for each year. Period $t$ identifies the starting year of the subprime mortgage crisis and the red vertical dashed line visually separates the pre-crisis and the post-crisis periods. Data on EU funds are only available after year $t$. All models include province fixed effects, year fixed effects, and macro region-year fixed effects. All figures report each point estimate of Mafia $\times(t+\tau)$ for the effect of mafia presence in a specific year together with the $90 \%$ (black), $95 \%$ (gray) and $99 \%$ (light gray) confidence intervals. Confidence intervals are based on spatially $(200 \mathrm{~km})$ and serially (11 years) correlated standard errors. 
Figure A.5: Spatial Correlogram for the Effect of Mafia Presence

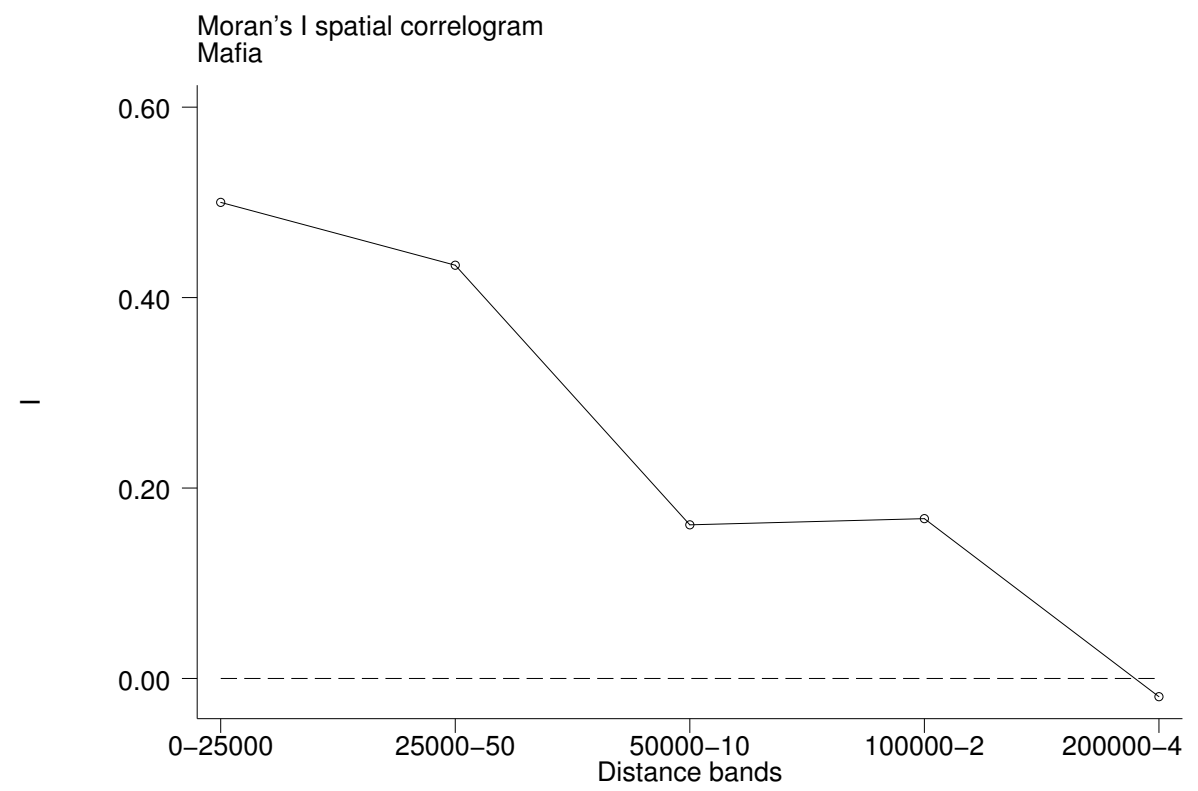

Note: This figure shows the Moran's I spatial correlogram for the effect of mafia presence. The figure shows five consecutive distance bands in meters, i.e. 0-25,000, 25,000-50,000, 50,000-100,000, 100,000-200,000 and 200,000-400,000. Distance is computed from the centroid of the main city in each province. 


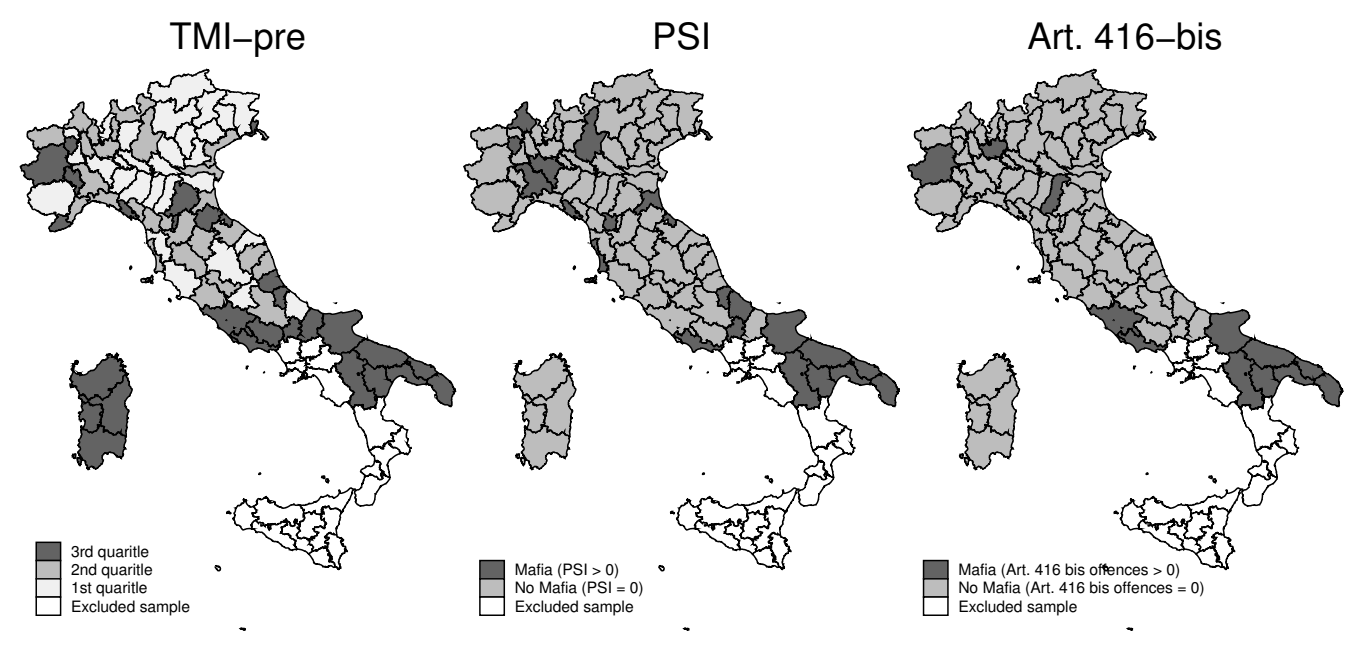

Note: This figure shows the geographical distribution of different measures for mafia presence. The figure shows the geographical distribution of the TMI-pre (left figure), the Power Syndicate Index (PSI) (central figure), and the number of cases pursuant to art.416-bis (right figure). White-colored provinces are those excluded from the sample. 
Figure A.7: Geographical Distribution of People Resettled by the Confino Law

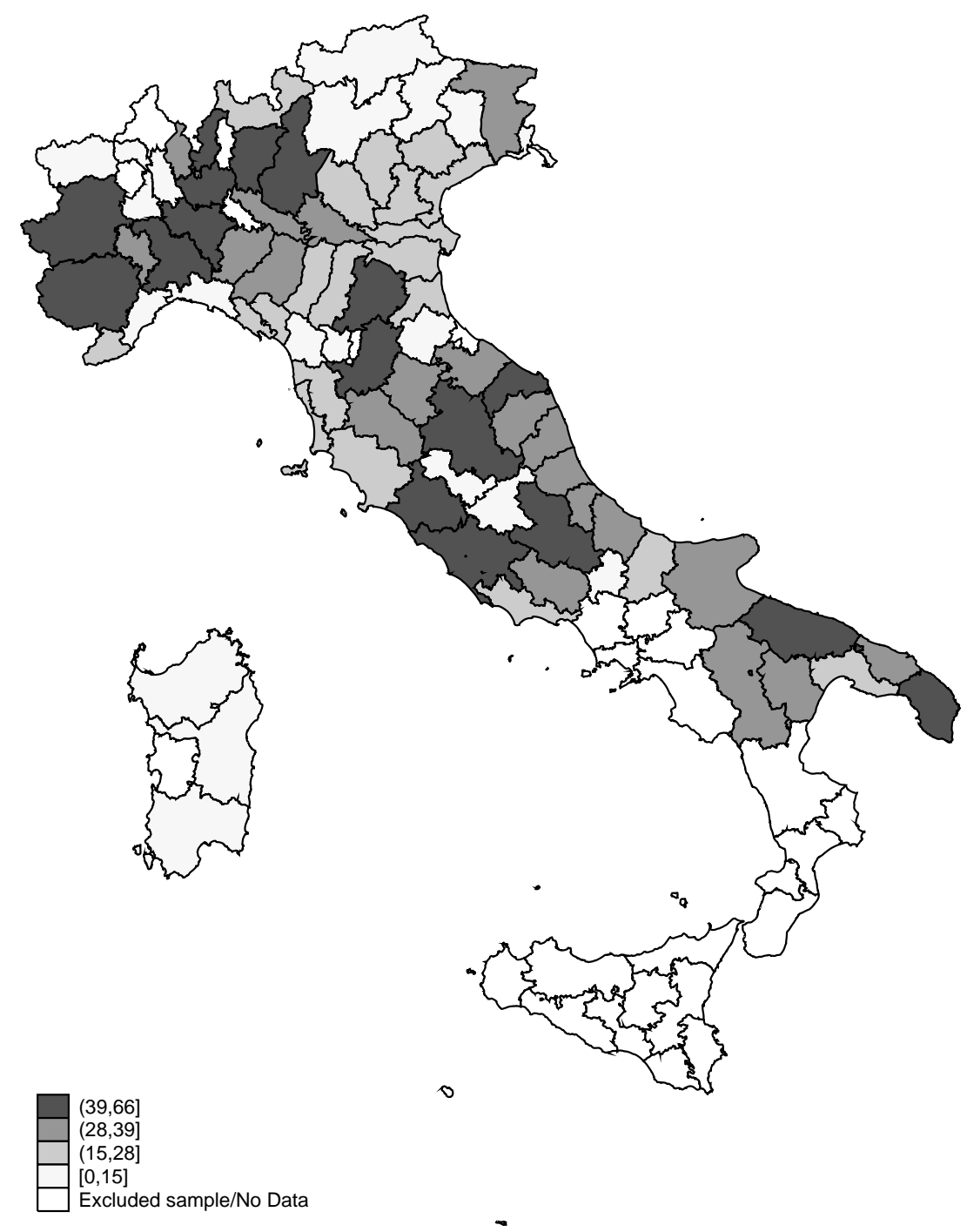

Note: This figure shows the geographical distribution of mafia members resettled by the confino law. The map shows the distribution of the total number of people resettled by the confino law across the Italian provinces during 1961-1974. The more intense the filling color of a province, the higher the number of people received by the province. White-colored provinces are provinces within the regions excluded from the baseline analysis or provinces not existing in 1974. 


\section{A.6 Additional Tables}

Table A.1: Summary Statistics

\begin{tabular}{lccccc}
\hline & $(1)$ & $(2)$ & $(3)$ & $(4)$ & $(5)$ \\
& Obs. & Mean & SD & Min. & Max. \\
\hline New enterprises (100,000 inh.) & 924 & 650 & 136 & 329 & 1,420 \\
Big banks (perc.) & 924 & 0.341 & 0.141 & 0.047 & 0.708 \\
Self-employed (perc.) & 924 & 0.268 & 0.045 & 0.026 & 0.445 \\
Turism index & 924 & 2.941 & 3.967 & 0.419 & 29.610 \\
Waste per capita (tons) & 924 & 0.547 & 0.107 & 0.050 & 0.876 \\
Trial duration (days) & 924 & 3,052 & 650 & 1,132 & 5,469 \\
Urban population (perc.) & 924 & 0.269 & 0.142 & 0.090 & 0.874 \\
Newspaper circulation (1,000 inh.) & 924 & 110 & 45 & 27 & 446 \\
Blood donations (Bags per 100 inh.) & 924 & 3.771 & 1.749 & 0.780 & 6.862 \\
\hline
\end{tabular}

Note: This table shows the summary statistics of the sample of this study. The sample is made by 84 Italian provinces observed yearly during 2003-2013. For each variable the table reports the sample size (Obs.), the average value (Mean), the standard deviation (SD), the minimum (Min.) and the maximum (Max.). 


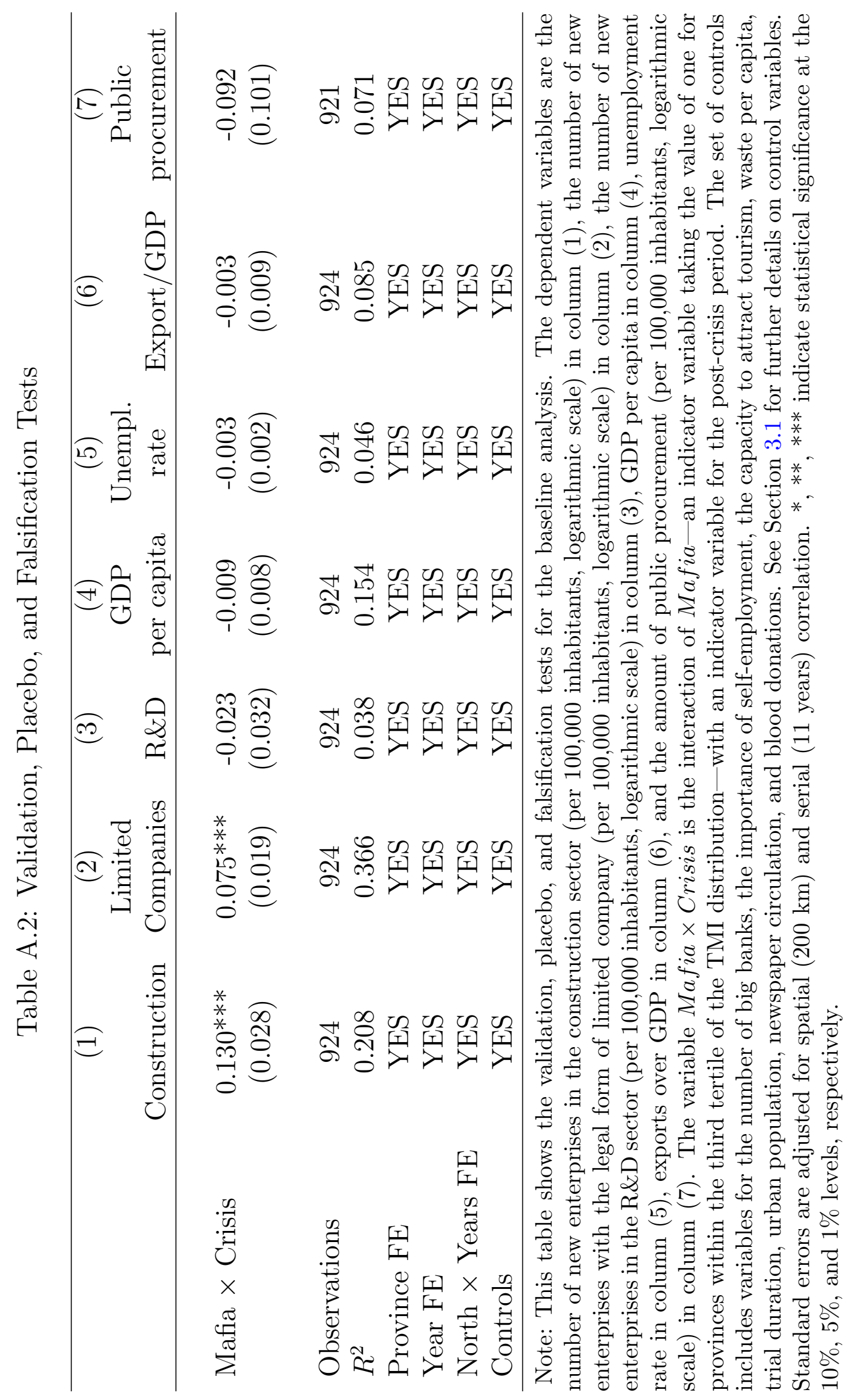

